\title{
An Evaluation of 30 Clinical Drugs Against the Comprehensive in vitro Proarrhythmia Assay Proposed Ion Channel Panel
}

William J. Crumb Jr., Ph.D. ${ }^{1}$, Jose Vicente, MSc, ${ }^{2}$ Lars Johannesen Ph.D., ${ }^{2}$ David Strauss, M.D., Ph.D. ${ }^{2}$

${ }^{1}$ Cytocentrics, New Orleans, LA

${ }^{2}$ Office of Clinical Pharmacology, Office of Translational Sciences, Center for Drug Evaluation and Research, U.S. Food and Drug Association, Silver Spring, MD

Correspondence:

William J. Crumb Jr., Ph.D.

Cytocentrics Inc.

1441 Canal St.

New Orleans, LA 70112

(504) 885-0585 (phone)

w.crumb@cytocentrics.com

Running title: Evaluation of CiPA Ion Channel Panel 


\begin{abstract}
Introduction: The Comprehensive in vitro Proarrhythmia Assay (CiPA) is intended to address the misidentification of drug-associated torsade de pointes risk based solely on hERG and QT data. This new paradigm will consist of four interrelated components, one of which is a panel consisting of six ion channels whose currents are important in both depolarization and repolarization of the cardiac action potential. This study examined the effects of 30 clinical drugs on these ion channels.
\end{abstract}

Methods: Ion currents were evaluated in expression systems using the manual whole cell patch clamp technique. Currents were elicited using either a ventricular action potential waveform or step-ramp voltage protocols.

Results: Of the seven ion currents studied, hERG was the most often blocked current followed by Nav1.5-late, and Cav1.2. Using a $20 \%$ reduction in current amplitude as an arbitrary maker, at a free plasma $C_{\max }$ concentration, no drug tested blocked Nav1.5-peak, KvLQT1/mink, Kir2.1 and $\mathrm{Kv} 4.3$ by that amount. At a $3 \mathrm{x}$ free plasma $\mathrm{C}_{\max }$, every current except Kir2.1 had at least one drug reduce current amplitude by at least $20 \%$.

Discussion: This is the first study of its kind to examine the effects of 30 clinical drugs against the seven ion currents currently proposed to makeup the CiPA ion channel panel. The results indicate the importance of drug-induced block of hERG, Nav1.5-late and Cav1.2 at clinically relevant concentrations, with low risk torsade drugs having equal or greater Nav1.5-late or Cav1.2 block compared to hERG block. In addition, the results of this study provide data which can be used to test the ability of various in silico models to predict drug-induced arrhythmias.

Key words: CiPA, electrophysiology, ion channels, manual patch clamp, torsade de pointes 


\section{Introduction}

The Comprehensive in vitro Proarrhythmia Assay (CiPA) is intended to address the misidentification of drug-associated torsade de pointes risk based solely on hERG and QT data (Sager et al., 2014). This new paradigm will consist of four interrelated components: an ion channel panel, in silico action potential reconstructions of the ion channel panel activity, and verification of results in stem cell derived human cardiomyocytes and in human phase 1 ECGs. To this end, the Safety Pharmacology Society organized the Ion Channel Working Group (ICWG) consisting of representatives from the pharmaceutical industry, regulatory agencies, contract research organizations, and academia. The ICWG was tasked with selecting the ion channels to be tested (Fermini et al., 2016). The ion channel panel decided upon consists of six ion channels whose currents are important in both depolarization and repolarization of the cardiac action potential ( $\mathrm{I}_{\mathrm{Kr}}, \mathrm{I}_{\mathrm{Na}}, \mathrm{I}_{\mathrm{Ca}}, \mathrm{I}_{\mathrm{Ks}}, \mathrm{I}_{\mathrm{to}}$ and $\mathrm{I}_{\mathrm{K} 1}$ ) (Fermini et al., 2016).

These currents contribute to all components of the cardiac action potential (Grant 2009, Nerbonne and Kass, 2005). Starting from a resting membrane potential, determined largely bythe inwardly rectifying potassium current $\left(\mathrm{I}_{\mathrm{K} 1}\right)$, the upstroke or $\mathrm{V}_{\max }$ of the cardiac action potential is due to an influx of $\mathrm{Na}^{+}$ions through the $\mathrm{Na}$ channel ( $\mathrm{I}_{\mathrm{Na}}$-peak). This is followed by a rapid phase of repolarization or phase 1 due to the efflux of $\mathrm{K}^{+}$ions through the transient outward potassium current $\left(\mathrm{I}_{\mathrm{t}_{0}}\right)$. Following this is the plateau of the cardiac action potential carried by an influx of $\mathrm{Ca}^{++}$ions through the L-type $\mathrm{Ca}$ channel $\left(\mathrm{I}_{\mathrm{Ca}}\right)$ and to a smaller extent through an influx of $\mathrm{Na}^{+}$ions through the $\mathrm{Na}$ channel. This $\mathrm{Na}$ current flowing during the plateau period is commonly referred to as the late $\mathrm{Na}$ current ( $\left.\mathrm{I}_{\mathrm{Na}}-1 a t e\right)$. Blockade of both the Ltype $\mathrm{Ca}$ current and $\mathrm{I}_{\mathrm{Na}}-$ late have been associated with a reduction in QTc prolongation and torsade even in the presence of hERG block (Belardinelli et al, 2013, Gintant et al, 2006, 
Johannesen et al., 2015). The action potential returns to a resting state via an efflux of $\mathrm{K}^{+}$ions through both the rapid and slow components of the delayed rectifier potassium current $\left(\mathrm{I}_{\mathrm{Kr}}\right.$ and $\mathrm{I}_{\mathrm{Ks}}$, respectively). For ease of use across industry and academia, these currents are most often recorded in expression systems and not primary cardiac myocytes. Therefore, $\mathrm{I}_{\mathrm{K} 1}, \mathrm{I}_{\mathrm{Na}}$ (peak and late), $\mathrm{I}_{\mathrm{to}}, \mathrm{I}_{\mathrm{Ca}}, \mathrm{I}_{\mathrm{Kr}}$, and $\mathrm{I}_{\mathrm{Ks}}$ are routinely recorded using cell lines expressing Kir2.1, Nav1.5, Kv4.3, Cav1.2, hERG, and KvLQT1/mink, respectively.

The purpose of the present study was to evaluate the ion current blocking profile of thirty clinical drugs against these expressed ion channels using the manual patch clamp technique and to provide insight into which ion currents are more frequently blocked at concentrations corresponding to free plasma $\mathrm{C}_{\max }$ and multiples thereof. This could have preliminary implications for whether all 7 ion channel currents should be assessed for every drug under CiPA. In addition, the ion channel blocking patterns of drugs that have high, intermediate and low torsade de pointes risk is compared. Furthermore, the results presented in this study can be used to evaluate various in silico action potential models for their ability to define and categorize the arrthymogenic risk of the drugs tested here. 


\section{Methods}

The cloned equivalent of the human $\mathrm{I}_{\mathrm{Kr}}(\mathrm{hERG}-\mathrm{HEK})$, IKs (KvLQT1/mink-HEK), $\mathrm{I}_{\mathrm{Na}}$ (Nav1.5-HEK), $\mathrm{I}_{\text {to }}(\mathrm{Kv} 4.3-\mathrm{HEK}), \mathrm{I}_{\mathrm{K} 1}(\mathrm{Kir} 2.1-\mathrm{CHO})$, and the L-type $\mathrm{I}_{\mathrm{Ca}}(\mathrm{Cav} 1.2-\mathrm{CHO})$ were used in this study. Cells were obtained from Cytocentrics Bioscience GmbH (Joachim-Jungius-Straße 9, 18059 Rostock, Germany).

\subsection{Internal and External Recording Solutions}

The external (bath) solution for hERG, KvLQT1/minK, Kir2.1, Kv4.3 had a composition of in mM: $\mathrm{NaCl} 137, \mathrm{KCl} 4, \mathrm{MgCl}_{2} 1, \mathrm{CaCl}_{2} 1.8$, HEPES 10, dextrose 11 with a $\mathrm{pH}$ of 7.4 $(\mathrm{NaOH})$. The internal (pipette) solution had a composition of (in $\mathrm{mM}$ ): $\mathrm{KCl} 130, \mathrm{MgCl}_{2} 1, \mathrm{NaCl}$ 7, HEPES 5, EGTA 5 with a pH of $7.2(\mathrm{KOH})$. The external solution for Cav1.2 and Nav1.5 had a composition of in mM: $\mathrm{NaCl} 137, \mathrm{KCl} 4, \mathrm{MgCl}_{2} 1, \mathrm{CaCl}_{2} 1.8, \mathrm{HEPES} 10$, dextrose 11 with a $\mathrm{pH}$ of $7.4(\mathrm{NaOH})$. The internal solution was (in mM): $\mathrm{CsCl} 130, \mathrm{MgCl}_{2}$ 1, $\mathrm{NaCl} 7, \mathrm{HEPES} 5$, EGTA 5 with a pH of $7.2(\mathrm{CsOH})$. In Cav1.2 experiments, $1.8 \mathrm{mM} \mathrm{CaCl}_{2}$ was replaced with $4 \mathrm{mM} \mathrm{BaCl}_{2}$. Chemicals were obtained from either Sigma-Aldrich (MA) or Fisher Scientific (PA).

\section{$2.2 \quad$ Test Compounds}

Test compounds were obtained from either Tocris Biosciences (MN) (dofetilide, quinidine, ranolazine, verapamil, mexiletine, lidocaine, diltiazem) or Sigma-Aldrich (MA) (all others). Compounds were dissolved in either de-ionized $\mathrm{H}_{2} \mathrm{O}$ or DMSO to create master stock solutions. This stock was subdivided into aliquots which were stored frozen until use. Dilutions of the master stock to create the final test concentrations were performed on the day of 
experimentation. Compounds were tested at four different concentrations (free plasma $\mathrm{C}_{\max }$ and 3 multiples of $\mathrm{C}_{\max }$ (see Table 1).

\subsection{Data Acquisition and Analysis}

Experiments $(n=3-6)$ were performed at $36 \pm 1{ }^{\circ} \mathrm{C}$ with the exception of $\mathrm{Kv} 4.3$ which was performed at $22 \pm 1^{\circ} \mathrm{C}$. This was done because separation of the $\mathrm{Kv} 4.3$ ionic current from the capacitivie current could not be done at $36^{\circ} \mathrm{C}$, making it impossible to measure current amplitude accurately. Currents were measured using the whole-cell variant of the patch clamp method as previously described (Crumb et al., 1995). Glass pipettes were pulled from borosilicate glass by a horizontal puller (Sutter Instruments, USA). Pipette tip resistance was approximately 1 to $2 \mathrm{M} \Omega$ when filled with internal solutions. Series resistance was compensated electronically by approximately 60-80\%. An Axopatch 1-B amplifier (Axon Instruments, Foster City, CA) was used for whole-cell voltage clamping. Creation of voltage clamp pulses and data acquisition was controlled by a computer running pClamp software (ver 9.2 Axon Instruments). After rupture of the cell membrane (entering whole-cell mode), current kinetics and amplitudes were allowed to stabilize (typically 3-5 minutes) as the cell was dialyzed with internal solution and the voltage protocol was applied every 10 seconds (applied at $0.1 \mathrm{~Hz}$ ). For Cav1.2 and KvLQT1/mink, currents which tend to exhibit more current rundown, the reduction in current amplitude typically occurred within the first minutes after rupture of the cell membrane. If present (>20\% current reduction), these cells were discarded. Only cells with a stable ionic current and stable holding current were used. The voltage protocols used to record the various currents are given in Panel A of Figures 1-7. A ventricular action potential waveform was used to elicit hERG, Cav1.2, and KvLQT1/mink (kindly provided by Dr. Gail Robertson, University 
of Wisconsin, insert link to pClamp protocol file). For Nav1.5 (peak and late), Kv4.3 and Kir2.1, the voltage protocols used were those proposed by the ICWG. For measurement of Nav1.5-late, current was elicited by the addition of $50 \mu \mathrm{M}$ veratridine to the external solution. Drug was applied to the bath solution via a rapid perfusion apparatus. Not all four concentrations were examined in every cell. Some currents were also examined for drug blocking effects by applying the pulse protocol every 1 second (applied at $1 \mathrm{~Hz}$ ). The drugs examined (quinidine, moxifloxacin, dofetilide, ranolazine, diltiazem, and verapamil) were those evaluated in recent clinical studies (Johannesen et al., 2014, 2016). Not all of these drugs were examined for every current at $1 \mathrm{~Hz}$.

Time-control experiments were performed for each current in which cells were exposed to non-drug containing external solution spiked with $0.1 \%$ DMSO for 5-8 minutes (the time period of a typical experiment).

Data are presented as \% reduction of current amplitude. This was measured as current reduction after an apparent steady-state effect has been reached in the presence of drug (or vehicle) relative to current amplitude before drug (or vehicle) was introduced (control). Each cell served as its own control. When possible (greater than $50 \%$ block in any cell was observed), a nonlinear curve-fitting routine was utilized to fit a three-parameter Hill equation to the results using R version 3.2.2 (R Foundation for Statistical Computing, Vienna, Austria). The equation is:

$$
y=V_{\max } \frac{x^{n}}{k^{n}+x^{n}}
$$

where $\mathrm{V}_{\max }=100, \mathrm{k}$, and $\mathrm{n}$ are unconstrained variables. Data tables with individual values for each drug are given in Supplement 1. 


\section{Results}

\section{1 hERG $\left(\mathbf{I}_{\mathbf{K r}}\right)$}

The hERG current is an important current in repolarization of the myocardium and the most common target for QT prolonging drugs. The effect of drugs on the amplitude of the hERG current was assessed using the protocol shown in Figure 1A. This voltage protocol elicited a current that peaked at voltages corresponding to the repolarization phase of the action potential (Figure 1B). As an example, addition of QT prolonging drug sotalol produced a concentrationdependent reduction of $\mathrm{hERG}$ current with an $\mathrm{IC}_{50}$ value of $86.4 \mu \mathrm{M}$ (Figure 1C). Figure 1D plots the percent $\mathrm{hERG}$ block associated with all 30 drugs at the free plasma $\mathrm{C}_{\max }$. As indicated, drugs commonly associated with QT prolongation produce a marked blockade of hERG current at therapeutic concentrations (e.g. quinidine, dofetilide). To assess the rate-dependence of hERG block, a subset of 6 drugs were evaluated at near $\mathrm{IC}_{50}$ concentrations by applying the voltage protocol every second. The block produced by quinidine $(0.3 \mu \mathrm{M})$, moxifloxacin $(70 \mu \mathrm{M})$, dofetilide $(2 \mathrm{nM})$, ranolazine $(6.9 \mu \mathrm{M})$, diltiazem $(12.5 \mu \mathrm{M})$, and verapamil $(0.5 \mu \mathrm{M})$ at $1 \mathrm{~Hz}$ was less than $6 \%$ greater than that observed at $0.1 \mathrm{~Hz}$, suggesting a lack of rate-dependent block of hERG current by these tested drugs at these rates. This however does not exclude the possibility that rate-dependent changes may be observed with other drugs. Time-control experiments indicate that over the time course of a typical experiment (5-6 minutes) hERG current amplitude was reduced by $2.5 \pm 1.9 \%$ (data not shown; $\mathrm{n}=6$ ).

\subsection{Nav1.5-late $\left(\mathbf{I}_{\mathrm{Na}}\right.$-late $)$}

The Na current flowing during the plateau of the action potential has been shown to contribute to action potential duration (APD). This current has been designated $\mathrm{I}_{\mathrm{Na}}$-late. 
Blockade of $\mathrm{I}_{\mathrm{Na}}$-late can shorten APD and QT, attenuate prolongations resulting from hERG block and prevent early afterdepolarizations. At $37^{\circ} \mathrm{C}$, Nav1.5 normally decays rapidly and within approximately $3 \mathrm{~ms}$ there is little measurable current remaining (Supplemental Figure 1A). In order to observe Nav1.5-late, the normal process of channel inactivation must be altered. This is typically done with a toxin such as ATX-II or veratridine (Chevalier et al., 2014; Belardinelli et al., 2013). In the present experiments, Nav1.5-late was elicited by the application of $50 \mu \mathrm{M}$ veratridine to the bath solution. In the presence of veratridine, $\mathrm{I}_{\mathrm{Na}}$ decays much more slowly and a measurable late current is easily observed (Supplemental Figure 1 A \& B). Furthermore, when measuring Nav1.5-late current $40 \mathrm{~ms}$ after initiation of a step to $-15 \mathrm{mV}$, there is a clear distinction between the peak and late components of Nav1.5 (Supplemental Figure 1B). As indicated in Figure 2, the most well described blocker of $\mathrm{I}_{\mathrm{Na}}$-late, ranolazine, concentrationdependently blocked Nav1.5-late with an $\mathrm{IC}_{50}$ of $7.9 \mu \mathrm{M}$. At free $\mathrm{C}_{\max }$ plasma concentrations, 5 drugs (quinine, ranolazine, flecainide, lidocaine and mexiletine) exhibited approximately a 10\% or greater blockade of Nav1.5-late and between approximately $25 \%$ to $50 \%$ blockade at $3 \mathrm{x}_{\max }$ (Figure 2D). To further verify that the current being measured $40 \mathrm{~ms}$ after the start of a pulse to $15 \mathrm{mV}$ was indeed Nav1.5-late, for 3 drugs the current amplitude was measured at $-15 \mathrm{mV}$ during the voltage ramp which is $342 \mathrm{~ms}$ after pulse initiation (see Figure $2 \mathrm{~A}$ ). The $\mathrm{IC}_{50}$ values for ranolazine, lidocaine, and mexiletine were $10.1 \mu \mathrm{M}, 8.4 \mu \mathrm{M}$, and $8.4 \mu \mathrm{M}$ when measured $342 \mathrm{~ms}$ after pulse initiation, respectively. This compares very well with values obtained $40 \mathrm{~ms}$ after pulse initiation (ranolazine: $7.9 \mu \mathrm{M}$, lidocaine: $10.8 \mu \mathrm{M}$, mexiletine: $8.9 \mu \mathrm{M}$ ). Time-control experiments of Nav1.5-late showed little change in current amplitude $(0.4 \pm 0.3 \%$ reduction, $\mathrm{n}=$ 8). 


\subsection{Cav1.2 $\left(\mathbf{I}_{\mathrm{CaL}}\right)$}

Cav1.2, which encodes the L-type $\mathrm{Ca}^{++}$channel, plays a critical role in the contraction of the myocardium and block of this current can attenuate the APD and QT prolonging effects of hERG blocking drugs. Initial experiments in which Cav1.2 was measured using $1.8 \mathrm{mM} \mathrm{Ca}^{++}$ indicated that a small amplitude current (typically $<200 \mathrm{pA}$ ), was elicited by the action potential waveform shown in Supplement Figure 2. For the purposes of the experiments described here, $\mathrm{Ca}^{++}$was replaced with $\mathrm{Ba}^{++}$to increase current amplitude and more easily allow pharmacological evaluation. This does not suggest that $\mathrm{Ba}^{++}$will be chosen as the charge carrier in the final CiPA assay. Using $\mathrm{Ba}^{++}$as a charge carrier, the inward current recorded was blocked by verapamil and exhibited a characteristic Cav1.2 current voltage (I-V) relationship (Supplement Figure 2). An example of the pharmacology of this channel is shown in Figure 3. As illustrated, diltiazem blocked Cav1.2 with an $\mathrm{IC}_{50}$ of $112 \mathrm{nM}$. Figure 3D illustrates that classic L-type $\mathrm{Ca}^{++}$channel blockers such as diltiazem and verapamil block Cav1.2 by approximately $20 \%$ or more at free plasma $\mathrm{C}_{\max }$. The rate-dependence $(1 \mathrm{~Hz})$ of Cav1.2 block was determined for the 2 L-type calcium channel blocking drugs, verapamil (150nM) and diltiazem (150nM). In the absence of drug, pacing at $1 \mathrm{~Hz}$ reduced Cav1.2 current amplitude by $29.2 \pm 6.7 \%(\mathrm{n}=6)$. In the presence of either diltiazem or verapamil, there was no additional relative block observed at a pacing rate of $1 \mathrm{~Hz}$ as compared to $0.1 \mathrm{~Hz}$ (diltiazem: $1.8 \pm 1.1 \%$, verapamil: $0 \pm 0 \%, \mathrm{n}=3$ ). Time-control experiments indicate that over the time course of a typical experiment Cav1.2 current amplitude was reduced by $2.0 \pm 1.2 \%(\mathrm{n}=4)$.

\subsection{Nav1.5-peak $\left(\mathbf{I}_{\mathrm{Na}}\right.$-peak $)$}


The rapidly activating component of the sodium current $\left(\mathrm{I}_{\mathrm{Na}}\right.$-peak) plays a critical role in depolarization of cardiac cells and conduction through the myocardium. Nav1.5-peak was recorded at physiologic temperatures $\left(36 \pm 1^{\circ} \mathrm{C}\right)$ and using $137 \mathrm{mM} \mathrm{NaCl}$ in the external solution. To evaluate whether proper voltage control was present under these conditions, I-V relationships were constructed (Supplement Figure 2D). As indicated, the I-V relationship under the present recording conditions exhibited typical characteristics for well controlled $\mathrm{I}_{\mathrm{Na}}$ with approximately 25-30mV between current activation and peak current amplitude and a reversal potential which appears to be very close to the predicted $+79 \mathrm{mV}$. The I-V relationship after addition of $1 \mu \mathrm{M}$ tetrodotoxin (TTX) is also shown. Flecainide reduced Nav1.5-peak with an $\mathrm{IC}_{50}$ of $6.7 \mu \mathrm{M}$ (Figure 4). At $\mathrm{C}_{\max }$ free plasma concentrations, all of the drugs examined blocked Nav1.5-peak by less than $20 \%$ (Figure 4D). Time controls were associated with a $2.3 \pm 2.3 \%$ reduction in Nav1.5-peak $(n=4)$. Rate-dependence at $1 \mathrm{~Hz}$ was determined for ranolazine $(23 \mu \mathrm{M})$, diltiazem $(12.5 \mu \mathrm{M})$, lidocaine $(10 \mu \mathrm{M})$, mexiletine $(10 \mu \mathrm{M})$, dofetilide $(6 \mathrm{nM})$, verapamil $(1 \mu \mathrm{M})$, quinidine $(5.4 \mu \mathrm{M})$, and moxifloxacin $(350 \mu \mathrm{M})$. There was less than a $10 \%$ additional reduction in Nav1.5peak current when paced at $1 \mathrm{~Hz}$ compared to $0.1 \mathrm{~Hz}$ for any of the drugs tested (range: $9.7 \pm$ $6.1 \%$ for quinidine, $1.2 \pm 1.2 \%$ for dofetilide, $\mathrm{n}=3$ ).

\section{$3.5 \quad \mathrm{Kv} 4.3\left(\mathrm{I}_{t_{\mathrm{o}}}\right)$}

Kv4.3 encodes the transient outward current $\left(\mathrm{I}_{\mathrm{to}}\right)$ which plays an important role in the rapid phase (phase 1) of action potential repolarization. The current elicited by the voltage protocol shown in Figure 5A, activated to a peak and then decayed characteristic of the $\mathrm{I}_{\mathrm{to}}$ recorded in human cardiac cells (Crumb et al., 1995). As indicated, quinine exhibited concentration-dependent block of $\mathrm{Kv} 4.3$ with an $\mathrm{IC}_{50}$ of $79.3 \mu \mathrm{M}$ (Figure $5 \mathrm{~B} \& \mathrm{C}$ ). Of the 30 
drugs tested, amitriptyline was associated with the greatest amount of Kv4.3 block at free plasma $\mathrm{C}_{\max }$ concentrations (Figure 5D). Time-control experiments showed a $2.3 \pm 2.0 \%$ reduction $(\mathrm{n}=$ 4) in current amplitude.

\subsection{KvLQT1/mink $\left(\mathbf{I}_{\mathrm{Ks}}\right)$}

KvLQT1/mink encodes the slow component of the delayed rectifier $\left(\mathrm{I}_{\mathrm{Ks}}\right)$ and plays a role in repolarization of the action potential. Figure 6B shows an example of KvLQT1/mink block. As indicated, the outward current elicited with the action potential waveform was blocked by quinine with an $\mathrm{IC}_{50}$ of $37.4 \mu \mathrm{M}$ (Figure $6 \mathrm{C}$ ). All of the drugs tested blocked $\mathrm{KvLQT1} / \mathrm{minK}$ by less than $20 \%$ at free plasma $\mathrm{C}_{\max }$ concentrations (Figure 6D). The rate-dependence $(1 \mathrm{~Hz})$ of KvLQT1/minK block was determined for the 2 blocking drugs, quinidine $(5.4 \mu \mathrm{M})$ and moxifloxacin $(70 \mu \mathrm{M})$. With either drug, there was little additional block observed at a pacing rate of $1 \mathrm{~Hz}$ as compared to $0.1 \mathrm{~Hz}$ (quinidine: $3.8 \pm 2.2 \%$, moxifloxacin: $2.6 \pm 2.6 \%, \mathrm{n}=3$ ). Time-control experiments showed an $8.2 \pm 0.4 \%$ reduction $(n=4)$ in current amplitude.

\subsection{Kir2.1 $\left(\mathbf{I}_{\mathbf{K} 1}\right)$}

Kir2.1 encodes the inwardly rectifying potassium current $\left(\mathrm{I}_{\mathrm{K} 1}\right)$ which helps to set the resting membrane potential in cardiac cells and also contributes to the terminal phase of repolarization of the action potential. Using the voltage protocol shown in Figure 7A, an inward current is activated that is blocked by chlorpromazine with an $\mathrm{IC}_{50}$ of $9.3 \mu \mathrm{M}$. As illustrated, none of the drugs tested reached a $10 \%$ mean blockade of Kir2.1 at free plasma $C_{\max }$ concentrations (Figure 7D). 


\subsection{Relative incidence of channel block}

It is important to gain insight into the relative frequency with which the ion currents which have been suggested to be included in routine screening are affected by these 30 drugs. Taking a 20\% reduction in current amplitude as an arbitrary marker, the relative frequency with which the tested ion currents were blocked at any concentration, $1 \mathrm{x}$ therapeutic free plasma $\mathrm{C}_{\max }$, and $3 \mathrm{x} \mathrm{C}_{\max }$ is shown in Figure 8. As expected, hERG is the most frequently blocked current. Nav1.5-late and Cav1.2 were the next most frequently blocked currents with approximately 4 times fewer drugs blocking by $20 \%$ or more at $1 \mathrm{x}$ and $3 \mathrm{x}$ free plasma $\mathrm{C}_{\max }$. In contrast, at $1 \mathrm{x}$ therapeutic $\mathrm{C}_{\max }$, the other currents tested were not blocked by $20 \%$ or more by any of the drugs

tested. At a $3 \mathrm{x}$ multiple of free plasma $\mathrm{C}_{\max }, \mathrm{Kv} 4.3$ was blocked approximately as frequently as Nav1.5-late and Cav1.2, while Nav1.5-peak and KvLQT1/mink were less frequently blocked. Kir2.1 was not blocked by any drug tested by $20 \%$ or more at a $3 \mathrm{x}$ multiple of free plasma $\mathrm{C}_{\max }$.

\subsection{Relationship between channel block and arrhythmic risk}

The relationship between ion channel block and proarrhythmic risk was examined for a subset of 12 drugs that were rated by the CiPA clinical working group to have low, intermediate or high risk of torsade de pointes. As indicated in Figures 9 and 10, at both a $1 \mathrm{X}$ and a $3 \mathrm{X}$ free plasma $\mathrm{C}_{\max }$ concentration, drugs which are classified as possessing a high risk for proarrhythmic events are associated with a large and rather selective block of hERG. In contrast, drugs in the low risk category block either Cav1.2 or Nav1.5-late more so or to a similar degree as $\mathrm{hERG}$ at $\mathrm{C}_{\max }$. Drugs in the intermediate category block hERG more than other currents but on average are associated with less $\mathrm{hERG}$ block at $\mathrm{C}_{\max }$ than members of the high risk category. Of note, the $40 \%$ percent hERG block shown in Figure 9 for terfenadine (intermediate risk drug) 
is associated with a $\mathrm{C}_{\max }$ of $9 \mathrm{nM}$, a concentration only achieved after metabolic inhibition. However, a more standard $\mathrm{C}_{\max }$ of $0.3 \mathrm{nM}$ is only associated with $8 \%$ hERG block, which could contribute to it being an intermediate versus high risk drug. Other factors such as the kinetics of drug binding to the hERG channel may also be important for differentiating intermediate from high risk drugs.

\section{Discussion}

For more than a decade, the cardiac potassium channel hERG has been the focus of both regulatory agencies and drug developers. While this attention has been warranted since drug induced blockade of this channel has been associated with QT prolongation and in rare cases torsade de pointes, the singular focus on this channel has likely led to unwarranted drug attrition and labeling (Stockbridge et al., 2013). In virtually all cases of drug-associated torsade de pointes, the offending drug has been shown to selectively block hERG at relevant plasma concentrations. However, there are drugs which block hERG and despite this activity are associated with little or no QT prolongation and minimal torsade de pointes risk, sometimes due to block of the L-type $\mathrm{I}_{\mathrm{Ca}}$ (e.g. verapamil) or $\mathrm{I}_{\mathrm{Na}}$-late (e.g. ranolazine). In the present study, we observed that the most frequently blocked channels at clinical free $\mathrm{C}_{\max }$ concentrations were hERG, Nav1.5-late and Cav1.2. While the substantial hit rate for hERG is expected, results from the present study using the manual patch clamp technique under physiologic conditions highlight for the first time that a large number of drugs also block Nav1.5-late and/or Cav1.2 currents, which can reduce the risk of torsade de pointes caused by hERG block (Antzelevich et al., 2004; Gintant et al., 2006; January and Riddle, 1989; Antoons et al., 2010; Fauchier et al., 1999). This is consistent with the four CiPA low risk drugs in this study having equal or greater Nav1.5-late 
block (ranolazine and mexiletine) or Cav1.2 block (verapamil, diltiazem) than hERG block, while the intermediate and high risk drugs had greater hERG block than other channels.

\subsection{Comparison to published data}

The results obtained in the present study were compared to previously published results (Kramer et al, 2013). While many of the drugs evaluated in the present study have published data for various ion channels, the Kramer et al. dataset has many of the drugs tested here and contains data on hERG, Nav1.5-peak, and Cav1.2. As indicated in Table 2, with few exceptions, the $\mathrm{IC}_{50}$ values from the 2 studies are very similar. One notable exception is dofetilide, which has an $\mathrm{IC}_{50}$ value for block of $\mathrm{hERG}$ in the present study $(2 \mathrm{nM})$ which is approximately 15 times lower than in the Kramer et al. study (30nM). The results obtained from the present study are consistent with the free plasma levels of dofetilide $(2.7 \mathrm{nM})$ associated with an approximately 75 ms increase in QTc (Johannesen et al., 2014).

The overall similarity in results observed for the 16 drugs in common between the 2 studies is interesting given the very different experimental methods. In the present study, all 3 currents were measured using the manual patch clamp technique at approximately $36^{\circ} \mathrm{C}$ using either an action potential waveform (hERG, Cav1.2) or a step-pulse (Nav1.5-peak). In the Kramer et al. study, data was obtained using an automated patch clamp platform at room temperature and using step-pulse voltage protocols. These results suggest that for most of the drugs in Table 2, experimental parameters such as temperature, patch clamp platform, and voltage protocols do not exert a marked effect on $\mathrm{IC}_{50}$ values. This is somewhat comforting since ultimately the ion channel portion of the CiPA paradigm is expected to be performed via 
automated patch platforms to accommodate large numbers of compounds and multiple channels. However, there could be greater differences when evaluating drug blocking kinetics.

Four antihypertensive/antianginal drugs with primary effects on the L-type Ca channel (Cav1.2) were evaluated in this study. Two of the four drugs exhibited substantial block of Cav1.2 at free plasma $\mathrm{C}_{\max }$ concentrations. For instance, diltiazem and verapamil had Cav1.2 $\mathrm{IC}_{50}$ values of $112 \mathrm{nM}$ and $202 \mathrm{nM}$ (respectively) and free plasma $\mathrm{C}_{\max }$ values of approximately $128 \mathrm{nM}$ and $45 \mathrm{nM}$, respectively. In contrast, mibefradil was associated with virtually no block of Cav1.2 at $12 \mathrm{nM}$ and an $\mathrm{IC}_{50}$ of $652 \mathrm{nM}$ (free plasma $\mathrm{C}_{\max }=10.6 \mathrm{nM}$ ). This is consistent with previous reports in myocytes in which mibefradil exerts a far greater effect on T-type calcium current than on the L-type (Leuranguer et al., 2001)). Bepridil showed only a $4.2 \%$ reduction in Cav1.2 at $30 \mathrm{nM}$ and an $\mathrm{IC}_{50}$ of $2.8 \mu \mathrm{M}$ (free plasma $\mathrm{C}_{\max }=31.5 \mathrm{nM}$ ). In guinea pig ventricular myocytes, bepridil blocks the L-type Ca current with an $\mathrm{IC}_{50}$ of 500nM (Yatani et al, 1986). These results suggest that a characterization of Cav1.2 to define the cardiac effects of L-type $\mathrm{Ca}^{++}$channel blockers is an appropriate surrogate for acutely isolated ventricular myocytes.

\subsection{Frequency of hits on ion currents}

To determine the frequency of blockade for the tested ion channel currents, the number of drugs producing a $20 \%$ reduction of a given current at any tested concentration was plotted (see Figure 8 ). The $20 \%$ reduction value is an arbitrary number but one commonly referred to in the literature (Redfern et al., 2003; Crumb et al., 2006). The results indicate that hERG was the current most frequently blocked, followed by Nav1.5-late and Cav1.2 each being blocked by greater than $60 \%$ of the drugs tested. Kir 2.1 was the least frequently blocked current. In addition, the frequency of block at $1 \mathrm{x}$ and $3 \mathrm{x}$ the free plasma $\mathrm{C}_{\max }$ was plotted. This showed a 
very different profile with hERG being blocked by $20 \%$ or more by $37 \%$ of the drugs and all other currents being blocked by less than $10 \%$ of the drugs tested. No drugs blocked Nav1.5peak, Kv4.3, LvLQT1/mink, or Kir2.1 by $20 \%$ or more at a $1 \times \mathrm{C}_{\max }$ concentration. At a $3 x \mathrm{C}_{\max }$ concentration, hERG was blocked by $70 \%$ of the drugs tested whereas all other currents were blocked by $20 \%$ or less of the drugs tested. None of the drugs tested blocked Kir 2.1 by $20 \%$ or more at a $3 \mathrm{x} \mathrm{C}_{\max }$ concentration.

\subsection{Stratification of safety risk}

Included in the drugs tested were 4 members from each of the CiPA risk categories (high, intermediate and low). These categories were based upon the risk of drug-associated torsade de pointes. We compared ion channel block against all tested ion currents at free plasma $\mathrm{C}_{\max }$ values of $1 \mathrm{x}$ and $3 \mathrm{x}$. This method has been used before on hERG, Cav1.2, and peak Nav1.5 using relative $\mathrm{IC}_{50}$ values. As indicated in Figures $9 \& 10$, members of the high risk category blocked hERG at therapeutic free plasma $\mathrm{C}_{\max }$ either exclusively or to a much greater extent than any other current examined. In the intermediate category, drug block of hERG was on average less than in the high risk category, supporting a lower risk of torsade de pointes. In the low risk category, the members were associated with a greater or equal block of either Cav1.2 or Nav1.5late when compared to block of hERG. These results clearly indicate the need for testing drug candidates against a panel of ion channels.

As indicated in Figures 9 and 10, the ion current blocking profile for some members of the intermediate torsade de pointes risk category is similar to that observed with some members of the high risk category. There are several possible reasons for this including (1) pharmacokinetic or drug interaction properties which may lead to higher plasma concentrations 
some in patients, (2) differences in risk factors in patient populations receiving each drug, (3) the assignment of drugs into high and intermediate risk categories may be imperfect, and (4) the kinetics of the drug block, particularly for hERG, may make some drugs more proarrhythmic than others. The kinetics of drug binding to the hERG channel and its ability to improve risk stratification is currently being investigated further by the CiPA ion channel and in silico working groups (Fermini et al. 2016).

In a recent clinical study of quinidine and dofetilide, the free plasma concentrations associated with the approximately $70 \%$ and $55 \%$ reduction in hERG current amplitude, respectively (see Figure 9) was associated with a79 ms and $74 \mathrm{~ms}$ increase in QTc (Johannesen et al., 2014) and T-wave morphology changes (Vicente et al., 2015). Furthermore, in the same study, ranolazine was associated with a $12 \mathrm{~ms}$ increase in QTc and verapamil was associated with no increase in QTc. The ion channel profile for verapamil supports the clinical results in that there is more block of Cav1.2 than hERG at therapeutic concentrations. The observation of a modest increase in QTc upon exposure to therapeutic concentrations of ranolazine suggests that the hERG block induced QTc prolongation is not completely counteracted by block of Nav1.5late, but is enough to counteract torsade de pointes risk. However, the QTc prolongation associated with ranolazine has a specific 'signature' that involves $\mathrm{T}_{\text {peak }}-\mathrm{T}_{\text {end }}$ prolongation without prolongation of the heart rate corrected $\mathrm{J}-\mathrm{T}_{\text {peak }}\left(\mathrm{J}-\mathrm{T}_{\text {peak }} \mathrm{c}\right)$ interval (Johannesen et al., 2014). Additional recent clinical study suggests that the $\mathrm{J}_{-} \mathrm{T}_{\text {peak }} \mathrm{c}$ interval is a better biomarker (than QTc) in assessing the balance of inward and outward current block and predictor of low torsade risk drugs (Johannesen et al., 2015). The CiPA clinical phase 1 ECG working group is expanding this analysis to additional drugs and will propose a framework for potential 
implementation of this new approach at an April 2016 Cardiac Safety Research Consortium meeting.

\subsection{Limitations}

The following are limitations of the present study. 1). The action potential waveform used was recorded from rabbit, and not human, ventricle. While this waveform has been used previously to characterize hERG (Zhou et al., 1998), we are cognizant that the data may be more relevant if a human ventricular AP was used instead. 2). Kv4.3 current was measured at room temperature and not physiologic temperature, as with the other ion currents. This was done to allow separation of the capacitive transient from peak Kv4.3 current. It is not known if the Kv4.3-drug interaction, for the drugs tested here, is temperature sensitive. 3). The drug effects on ion currents were tested at a pacing rate of $0.1 \mathrm{~Hz}$. This pacing rate was chosen because it is often used in the literature and it represents a common pacing rate for all currents tested that was not associated with significant rundown. However, currents were evaluated against some drugs at a pacing rate of $1 \mathrm{~Hz}$, which showed limited differences from the $0.1 \mathrm{~Hz}$ data. 4). Nav1.5-late was elicited by the use of veratridine. Although sodium channel inactivation modifiers such as veratridine and ATX-II are commonly used to increase the amplitude of late- $\mathrm{I}_{\mathrm{Na}}$, it is not known if they may interfere/alter the effects of late $\mathrm{I}_{\mathrm{Na}}$ blockers. 5). In the present study, drug-effects were not "washed out" to provide insight into whether the reduction in current amplitude was due to actual drug block or current rundown. However, time controls suggest that any reduction in current amplitude was due primarily to drug-related ion current block. Furthermore, not all drug blocking effects, particularly at higher concentrations, are able to be "washed out". 6). The $\mathrm{Ca}^{++}$and $\mathrm{Mg}^{++}$in the external solution can have blocking effects on hERG current (Ho et al., 
1998; Po et al., 1999). This may make it difficult in calculating the actual drug-hERG current blocking effects. However, the ion concentrations were physiologic and it is unlikely that $\mathrm{Ca}^{++}$ and $\mathrm{Mg}^{++}$will be absent in the plasma of individuals taking these drugs.

The in silico and ion channel working group for the CiPA initiative are currently studying voltage clamp protocols that model dynamic drug-ion channel interactions for hERG, and potentially for other channels (Fermini et al., 2016). Thus, final CiPA voltage clamp protocols for hERG, and potentially other channels, may differ substantially from those used in this study. However, a critical first step is to identify $\mathrm{IC}_{50}$ values or the maximal percent block at clinically relevant drug concentrations to determine which channels are the most important channels to be assessed under CiPA. While this ion channel data could also be entered into in silico models, such as the O'Hara-Rudy model (O'Hara et al., 2011), we elected to not do that here because it is beyond the scope of this manuscript and because the in silico proarrhythmia metrics have not been finalized. Rapidly publishing this data will allow any investigators to use it for in silico modeling. Finally, drugs were selected with a stratified risk of torsade de pointes, existing clinical ECG data, and with a range of ion channel effects. However, the hit rates for block of the different channels are only reflective of the 30 drugs in this study.

\subsection{Conclusion}

This is the first study of its kind to examine the effects of 30 clinical drugs against the 7 ion channel currents currently proposed to makeup the CiPA ion channel panel. The results of the present study highlight the importance of drug-induced block of hERG, Nav1.5-late and Cav1.2 at clinically relevant concentrations. These were the most frequently blocked currents and are likely the most important in terms of increased risk for torsade de pointes (blocking 
hERG) vs. decreasing risk (blocking Nav1.5-late and/or Cav1.2). This was consistent with the 12 CiPA drugs, where high and intermediate risk drugs had greater hERG block than other channels, while low risk drugs had equivalent or greater Nav1.5 block (ranolazine and mexiletine) or Cav1.2 block (verapamil, diltiazem) than hERG block. Nav1.5-peak block was the next most commonly blocked channel, and its importance in conduction and potential for use-dependent block that was not thoroughly assessed here, suggest that it also is important to be assessed under CiPA. Based upon the 30 drugs tested in this study, the less frequent hit rates for Kv4.3, KvLQT1/mink and Kir2.1 suggest that these channels may be less critical for assessment of all drugs under CiPA. This should be further evaluated with consideration of potential false positive hit rates along with the impact of block of these channels has on proarrhythmic risk in the CiPA in silico action potential model. 


\section{Acknowledgements}

The step ramp protocols used in this study were developed by the CiPA ion channel working group. The authors would like to thank Drs. Bernard Fermini, Najah Abi Gerges, Jules Hancox, Adam Hill, Jamie Vandenberg and Norman Stockbridge for their expert opinions and review of the manuscript. This project was supported by appointments to the Research Participation Programs at the Oak Ridge Institute for Science and Education through an interagency agreement between the Department of Energy and FDA. 


\section{References}

Antoons G, Oros A, Beelman JDM, et al. (2010) Late $\mathrm{Na}^{+}$Current Inhibition by Ranolazine Reduces Torsades de Pointes in the Chronic Atrioventricular Block Dog Model. Journal American College of Cardiolology, 55:801-809.

Antzelevitch, C. , Belardinelli L, Zygmunt AC, et al. (2004) Electrophysiological effects of ranolazine, a novel antianginal agent with antiarrhythmic properties. Circulation, 110:904-910.

Belardinelli L, et al. (2013) A Novel, Potent, and Selective Inhibitor of Cardiac Late Sodium Current Suppresses Experimental Arrhythmias. Journal of Pharmacology and Experimental Therapeutics, 344:23-32.

Chevalier M, Amuzescu B, Gawali V, et al. (2014) Late cardiac sodium current can be assessed using automated patch-clamp. F1000Research, 3:245. doi:10.12688/f1000research.5544.1.

Crumb WJ Jr, Pigott JD, Clarkson CW. (1995) Description of a nonselective cation current in human atrium. Circulation Research,77:950-6.

Crumb WJ, Ekins S, Sarazan RD, et al. (2006) Effects of Antipsychotic Drugs on $I_{\text {to }}, I_{\mathrm{Na}}, I_{\text {sus }}, I$ K1, and hERG: QT Prolongation, Structure Activity Relationship, and Network Analysis.

Pharmaceutical Research, 23:1133-1143.

Fauchier L, Babuty D, Autret ML, et al. (1999) Effect of verapamil on QT interval dynamicity. American Journal of Cardioliology, 83:807-808.

Fermini B, Hancox JC, Abi-Gerges N, et al. (2016) A New Perspective in the Field of Cardiac Safety Testing through the Comprehensive In Vitro Proarrhythmia Assay Paradigm. Journal of Biomolecular Screening, 21:1-11.

Gintant G, Su Z, Martin RL, Cox BF. (2006) Utility of hERG Assays as Surrogate Markers of Delayed Cardiac Repolarization and QT Safety. Toxicologic Pathology, 34:81-90.

Grant AO. (2009) Basic Science for the Clinical Electrophysiologist. Cardiac Ion Channels. Circulation: Arrhythmia and Electrophysiology, 2: 185-194.

Ho WK, Kim I, Lee CO \& Earm YE. (1998). Voltage-dependent blockade of HERG channels expressed in Xenopus oocytes by external Ca2+ and Mg2+. The Journal of Physiology 507 ( Pt 3), 631-638.

January CT, Riddle JM. (1989) Early afterdepolarizations: mechanism of induction and block. A role for L-type Ca2+ current. Circulation Research, 64:977-990.

Johannesen L, Vicente J, Mason JW, et al. (2014) Differentiating drug-induced multichannel block on the electrocardiogram: randomized study of dofetilide, quinidine, ranolazine, and verapamil. Clinical Pharmacolology and Therapeutics, 96:549-558. 
Johannesen L, Vicente J, Mason JW, et al. (2016) Late sodium current block for drug-induced long QT syndrome: Results from a prospective clinical trial. Clinical. Pharmacolology and. Therapeutics, 99:214-223.

Kramer J, Obejero-Paz CA, Myatt G, et al. (2013) MICE models: superior to the HERG model in predicting Torsade de Pointes. Science Reports, 3:2100.

LeuranguerV, Mangoni ME, Nargeot J et al., (2001) Inhibition of T-type and L-type calcium channels by mibefradil: physiologic and pharmacologic bases of cardiovascular effects. Journal of Cardiovascular Pharmacolology, 37:649-61.

Nerbonne JM, Kass RS. (2005) Molecular Physiology of Cardiac Repolarization. Physiological Reviews, 85:1205-1253.

O'Hara T, Virág L, Varró A, Rudy Y. (2011) Simulation of the undiseased human cardiac ventricular action potential: model formulation and experimental validation. PLoS Computational Biology, doi: 10.1371/journal.pcbi.1002061

Po SS, Wang DW, Yang IC, et al. (1999). Modulation of HERG potassium channels by extracellular magnesium and quinidine. Journal of Cardiovascular Pharmacology 33, 181-185.

Redfern WS, Carlsson L, Davis AS et al. (2003) Relationships between preclinical cardiac electrophysiology, clinical QT interval prolongation and torsade de pointes for a broad range of drugs: evidence for a provisional safety margin in drug development. Cardiovascular Research, 58:32-45.

Sager PT, Gintant G, Turner JR, et al. (2014) Rechanneling the cardiac proarrhythmia safety paradigm: A meeting report from the Cardiac Safety Research Consortium. American Heart Journal, 167:292-300.

Stockbridge N, Morganroth J, Shah RR et al. (2013) Dealing with global safety issues : was the response to QT-liability of non-cardiac drugs well coordinated? Drug Safety, 36:167-82.

Vicente J, Johannesen L, Mason JW, et al. (2015) Comprehensive T wave Morphology Assessment in a Randomized Clinical Study of Dofetilide, Quinidine, Ranolazine, and Verapamil. Journal American Heart Association, 4:e01615 doi: 10.1161.

Yatani A, Brown AM, Schwartz A. (1986) Bepridil block of cardiac calcium and sodium channels. Journal of Pharmacology Experimental Therapeutics, 237:9-17.

Zhou, Z., Gong, Q., Ye, B., et al. (1998) Properties of HERG channels stably expressed in HEK 293 cells studied at physiological temperature. Biophysical Journal, 74: 230-241. 
Table 1.

The following test concentrations were used (in $\mathrm{nM}$ ):

\begin{tabular}{|l|l|l|l|l|l|}
\hline Drug & Free $\mathrm{C}_{\max }$ & Dose 1 & Dose 2 & Dose 3 & Dose 4 \\
\hline Amiodarone & 0.7 & 0.8 & 80 & 800 & 8000 \\
\hline Amitryptiline & 36.4 & 36 & 360 & 3600 & 36000 \\
\hline Azithromycin & 1937.0 & 2000 & 20000 & 100000 & 300000 \\
\hline Bepridil & 31.5 & 30 & 180 & 900 & 3000 \\
\hline Chloroquine & 249.5 & 250 & 750 & 2500 & 25000 \\
\hline Chlorpromazine & 34.5 & 35 & 350 & 1750 & 10500 \\
\hline Cibenzoline & 673.0 & 600 & 1800 & 6000 & 60000 \\
\hline Cisapride & 2.6 & 2.5 & 7.5 & 25 & 125 \\
\hline Diltiazem & 127.5 & 20 & 150 & 500 & 12500 \\
\hline Dofetilide & 2.1 & 0.1 & 1 & 2 & 3 \\
\hline Flecainide & 752.9 & 200 & 1000 & 4000 & 20000 \\
\hline Lidocaine & 703.7 & 625 & 2500 & 5000 & 10000 \\
\hline Lopinavir & 2560.4 & 700 & 2100 & 7000 & 35000 \\
\hline Mexiletine & 2503.2 & 625 & 2500 & 5000 & 10000 \\
\hline Mibefradil & 10.6 & 12 & 120 & 1200 & 12000 \\
\hline Moxifloxacin & 3562.5 & 7000 & 21000 & 70000 & 350000 \\
\hline Nilotinib & 60.4 & 60 & 300 & 1800 & 6000 \\
\hline Ondansetron & 358.5 & 200 & 1000 & 4000 & 20000 \\
\hline Propafenone & 130.9 & 130 & 390 & 1300 & 6500 \\
\hline Quinidine & 842.9 & 300 & 900 & 2700 & 5400 \\
\hline Quinine & 3956.7 & 4000 & 12000 & 40000 & 200000 \\
\hline Ranolazine & 1948.2 & 575 & 2300 & 6900 & 23000 \\
\hline Ritonavir & 436.9 & 400 & 1200 & 4000 & 20000 \\
\hline Rufinamide & 83126.9 & 80000 & 240000 & NS & NS \\
\hline Saquinavir & 417.2 & 400 & 1200 & 4000 & 20000 \\
\hline Sertindole & 1.6 & 1.5 & 4.5 & 15 & 75 \\
\hline Sotalol & 14686.4 & 14000 & 140000 & 700000 & 2100000 \\
\hline Terfenadine & 0.3 & 0.8 & 8 & 80 & 800 \\
\hline Toremefine & 26.3 & 25 & 75 & 250 & 1250 \\
\hline Verapamil & 45.0 & 5 & 50 & 150 & 500 \\
\hline NS, not soluble & & & & \\
\hline
\end{tabular}

NS, not soluble

Additional concentrations were added for some of the drugs and some currents as indicated in the Tables in Supplement 1. 


\section{Table 2.}

Comparison of $\mathrm{IC}_{50}$ values

\begin{tabular}{|l|l|l|l|}
\hline Drug & hERG & Cav1.2 & Nav1.5-peak \\
\hline Amiodarone & $0.9 / 0.9$ & $1.3 / 1.9$ & $4.6 / 15.9$ \\
\hline Bepridil & $0.2 / 0.2$ & $2.8 / 1.0$ & $2.9 / 2.3$ \\
\hline Chlorpromazine & $1.1 / 1.5$ & $8.2 / 3.4$ & $4.5 / 3.0$ \\
\hline Cisapride & $0.01 / 0.02$ & $>0.13 / 11.8$ & $>0.13 / 337.0$ \\
\hline Diltiazem & $6.6 / 53.2$ & $0.1 / 0.8$ & $>12.5 / 22.4$ \\
\hline Dofetilide & $0.002 / 0.03$ & $>0.006 / 26.7$ & $>0.006 / 54.2$ \\
\hline Flecainide & $0.7 / 1.5$ & $>20 / 27.1$ & $6.7 / 6.2$ \\
\hline Mibefradil & $0.3 / 1.7$ & $0.7 / 0.5$ & $8.5 / 5.6$ \\
\hline Moxifloxacin & $92.7 / 86.2$ & $>350 / 173.0$ & $>350 / 1112.0$ \\
\hline Nilotinib & $0.1 / 1.0$ & $>6 / 17.5$ & $>6 / 13.3$ \\
\hline Quinidine & $0.3 / 0.7$ & $>5.4 / 6.4$ & $>5.4 / 14.6$ \\
\hline Saquinavir & $3.4 / 16.9$ & $3.2 / 1.9$ & $15.6 / 12.1$ \\
\hline Sertindole & $0.01 / 0.03$ & $>0.08 / 6.3$ & $>0.08 / 6.9$ \\
\hline Sotalol & $86.3 / 111.4$ & $>2100 / 193.3$ & $>2100 / 7013.9$ \\
\hline Terfenadine & $0.02 / 0.05$ & $0.7 / 0.9$ & $>0.8 / 2.0$ \\
\hline Verapamil & $0.7 / 0.3$ & $0.1 / 0.2$ & $>1.0 / 32.5$ \\
\hline
\end{tabular}

All values are $\mathrm{IC}_{50}$ values or the highest concentration tested (in $\mu \mathrm{M}$ ). First value in each pair is from the present study, second value from Kramer et al., 2013. In some cases in the present study and $\mathrm{IC}_{50}$ value was not reached. In those cases, the $\mathrm{IC}_{50}$ value is designated as being > than the highest concentration tested. 
A

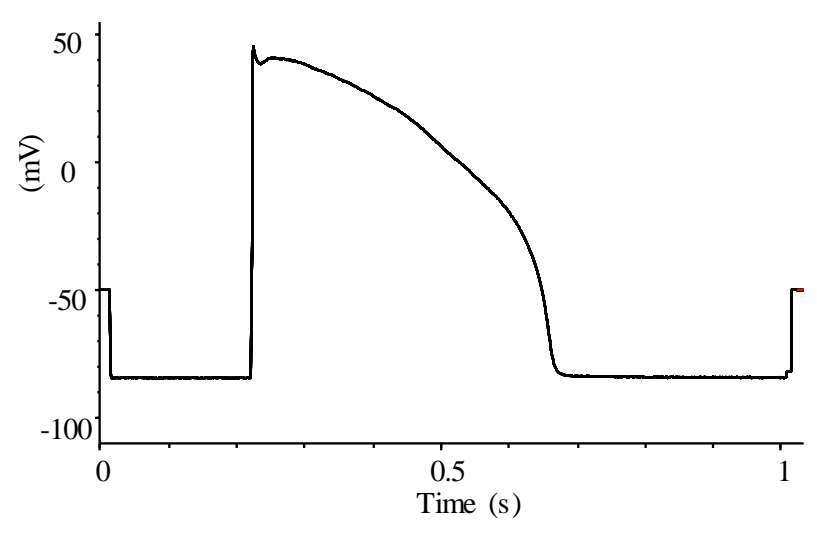

B

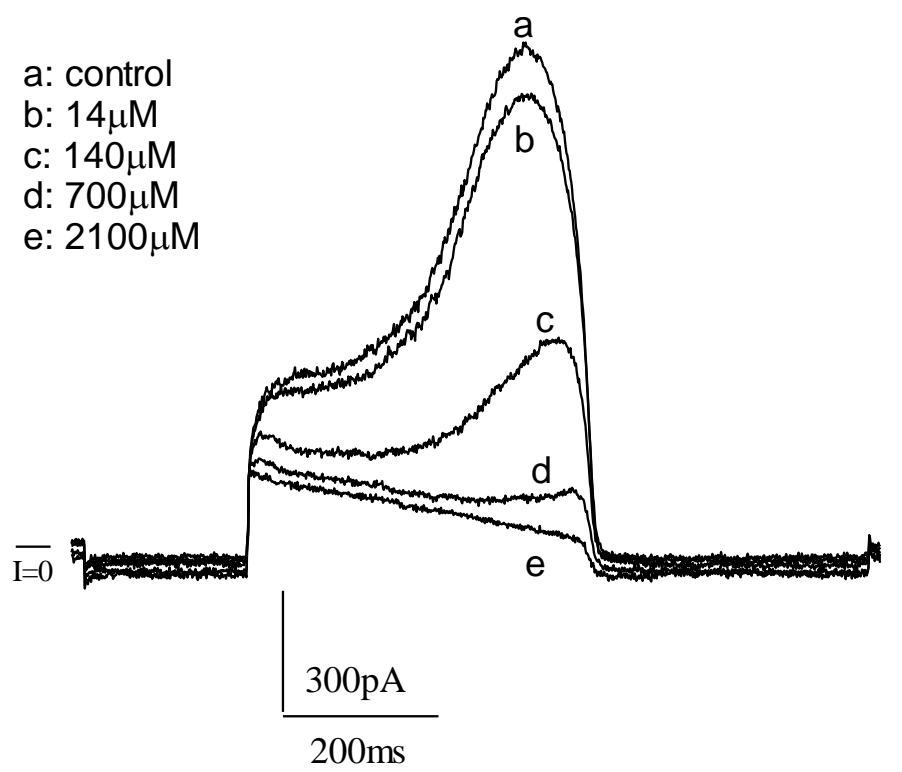

C

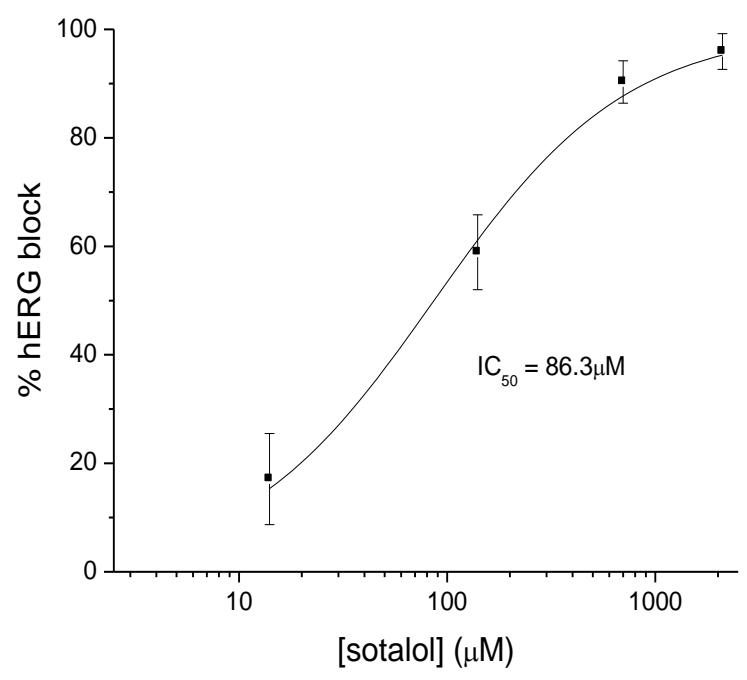

D

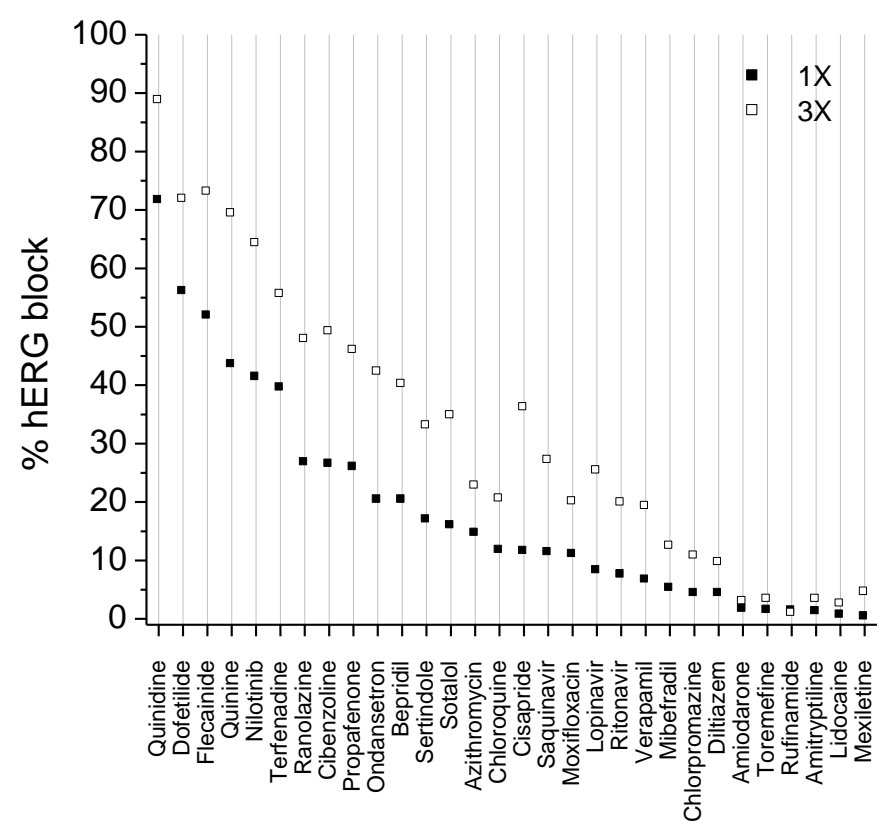


Figure 1: $\quad h E R G$ current $\left(\mathrm{I}_{\mathrm{Kr}}\right)$ block by the 30 drug panel. A. Action potential waveform used to elicit $\mathrm{hERG}$ current at $36 \pm 1^{\circ} \mathrm{C}$. B. Example of the effects of sotalol on hERG current. I $=0$ represents zero current. Peak outward current was measured. C. Concentration-response relationship for sotalol block of hERG. Fit equation is given in the Methods. D. Amount of hERG current block produced by $1,3 \mathrm{X}$ multiples of $\mathrm{C}_{\max }$ free plasma concentrations for each member of the 30 drug panel (data derived from Tables in Supplement). 
A

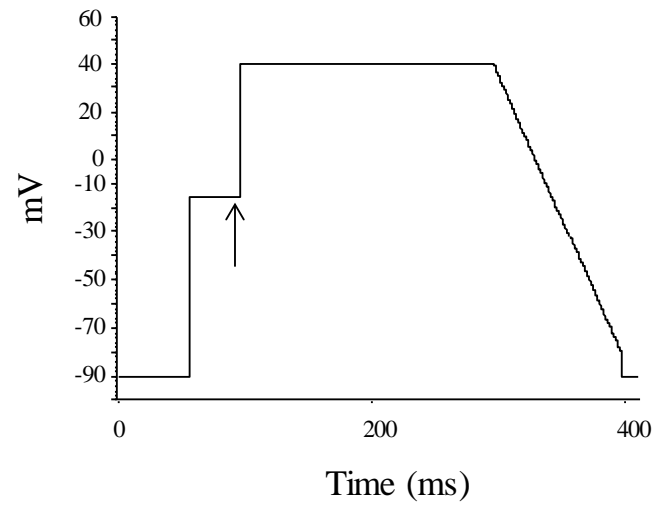

B

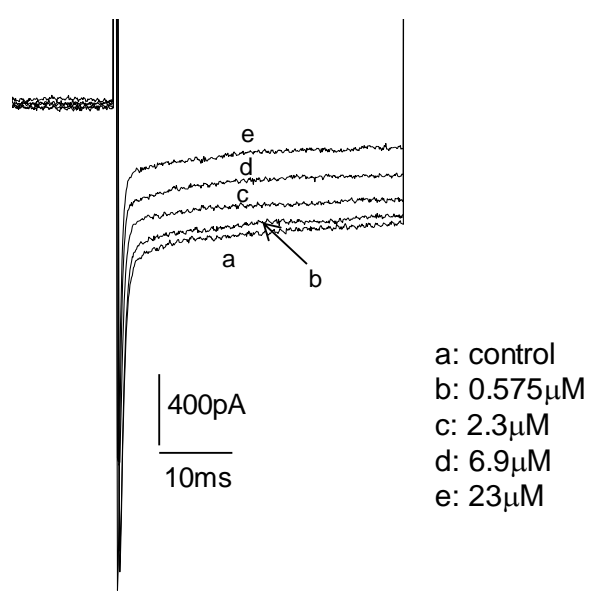

C

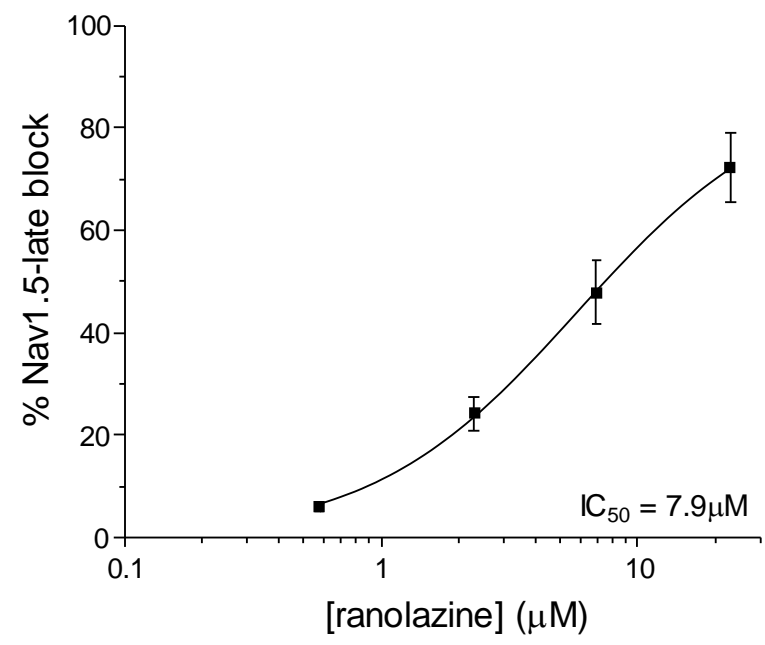

D

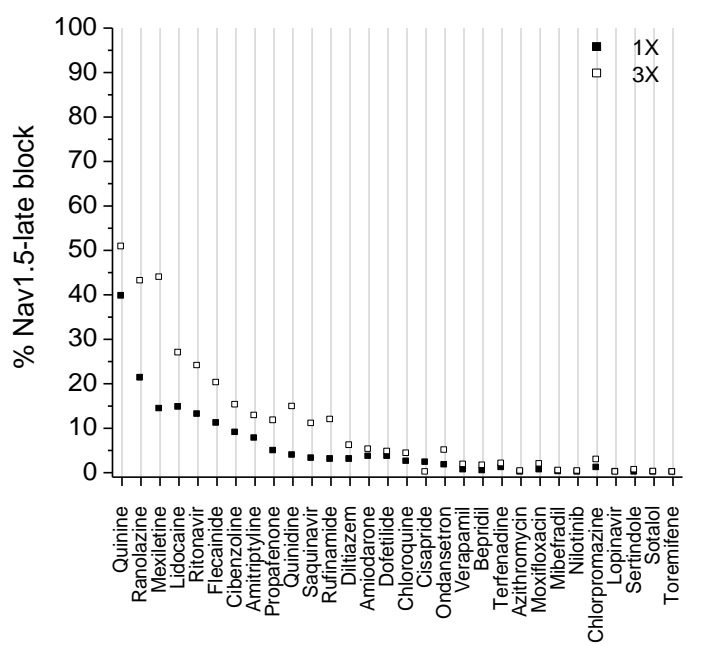

Figure 2: Nav1.5-late current $\left(\mathrm{I}_{\mathrm{Na}}\right.$-late) block by the 30 drug panel. A. Voltage protocol used to elicit current at $36 \pm 1{ }^{\circ} \mathrm{C}$. Arrow indicates where current was measured. B. Example of the effects of ranolazine on Nav1.5-late current. Only current during the step to $-15 \mathrm{mV}$ is shown. Current was measured at the end of the step to $-15 \mathrm{mV}$. C. Concentration-response relationship for ranolazine block of Nav1.5-late. Fit equation is given in the Methods. D. Amount of Nav1.5late current block produced by 1, 3X multiples of $\mathrm{C}_{\max }$ free plasma concentrations for each member of the 30 drug panel (data derived from Tables in Supplement). 
A

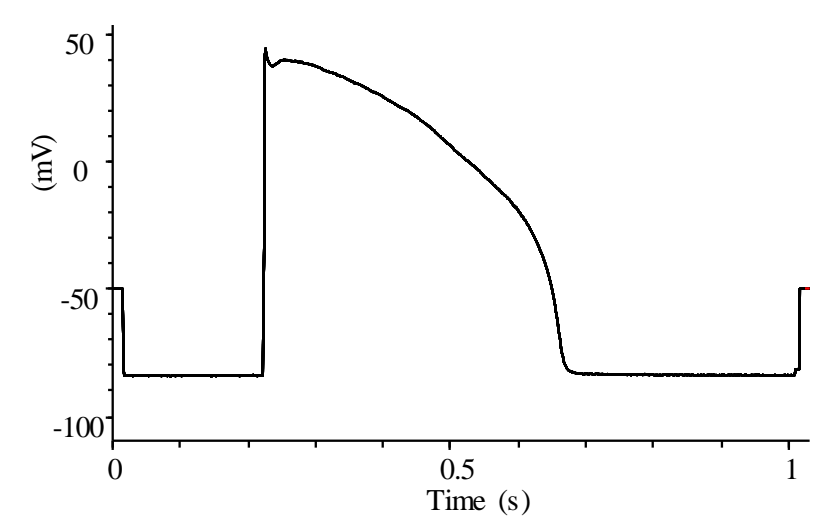

B

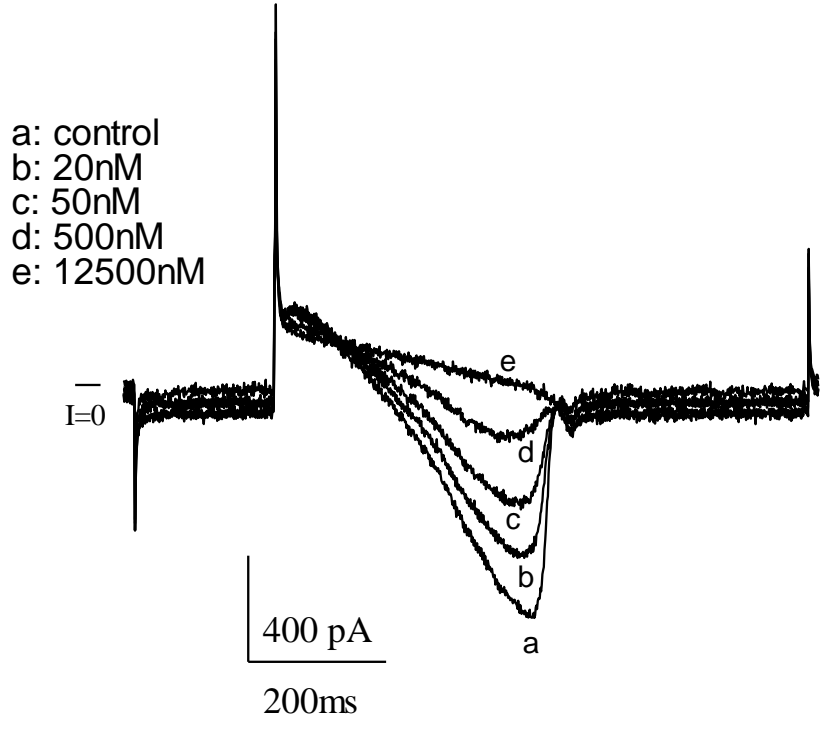

C

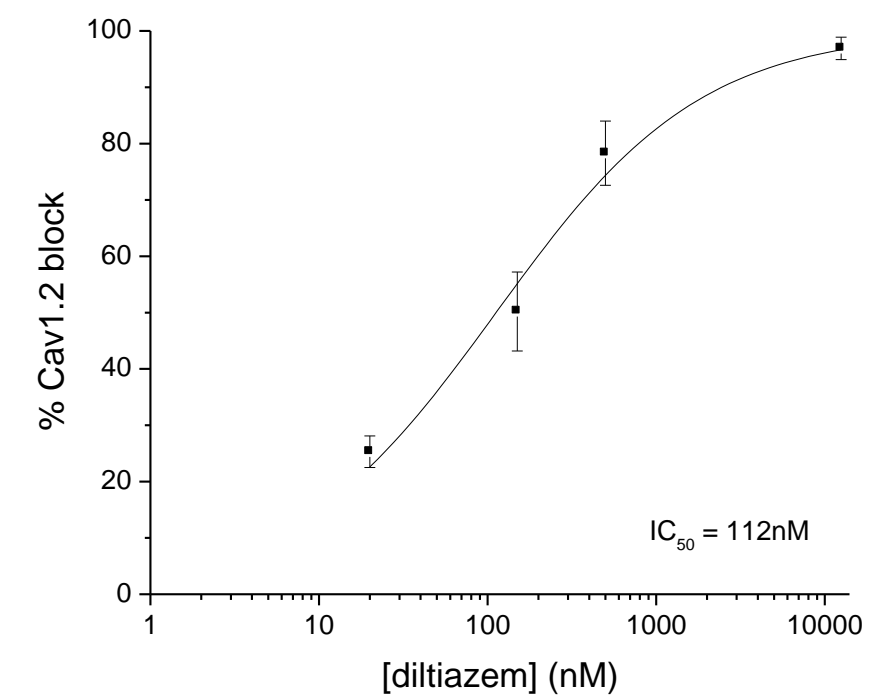

D

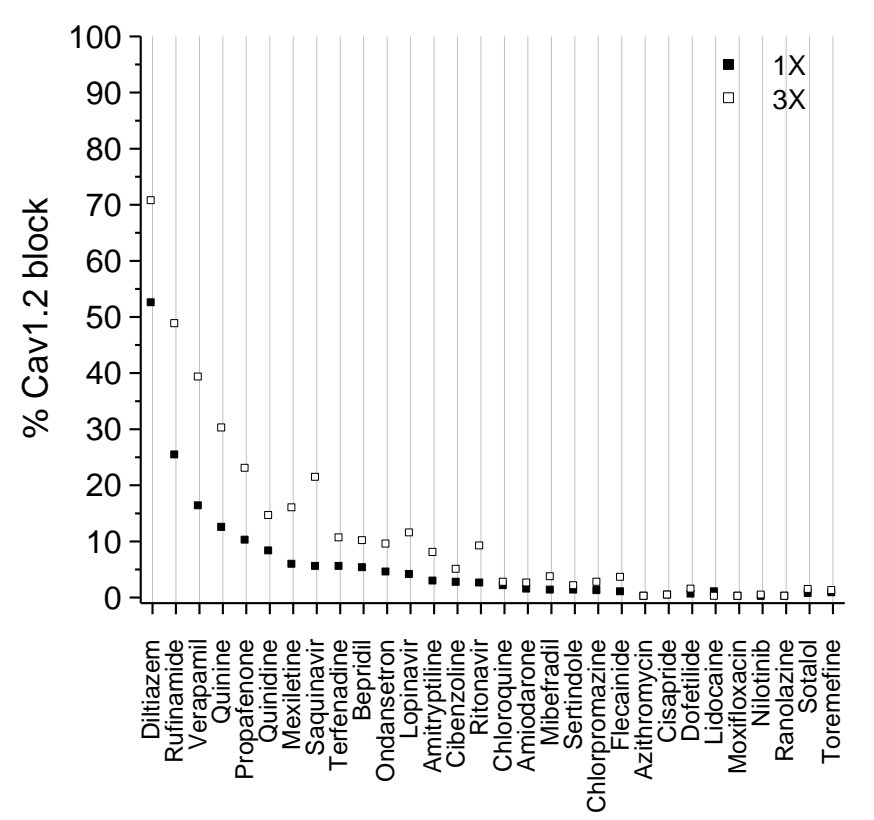


Figure 3: Cav1.2 current (L-type $\mathrm{I}_{\mathrm{Ca}}$ ) block by the 30 drug panel. A. Action potential waveform used to elicit Cav1.2 current at $36 \pm 1^{\circ} \mathrm{C}$. B. Example of the effects of diltiazem on Cav1.2 current. I $=0$ represents zero current. Peak inward current was measured. C. Concentration-response relationship for diltiazem block of Cav1.2. Fit equation is given in the Methods. D. Amount of Cav1.2 current block produced by 1, 3X multiples of $\mathrm{C}_{\max }$ free plasma concentrations for each member of the 30 drug panel (data derived from Tables in Supplement). 

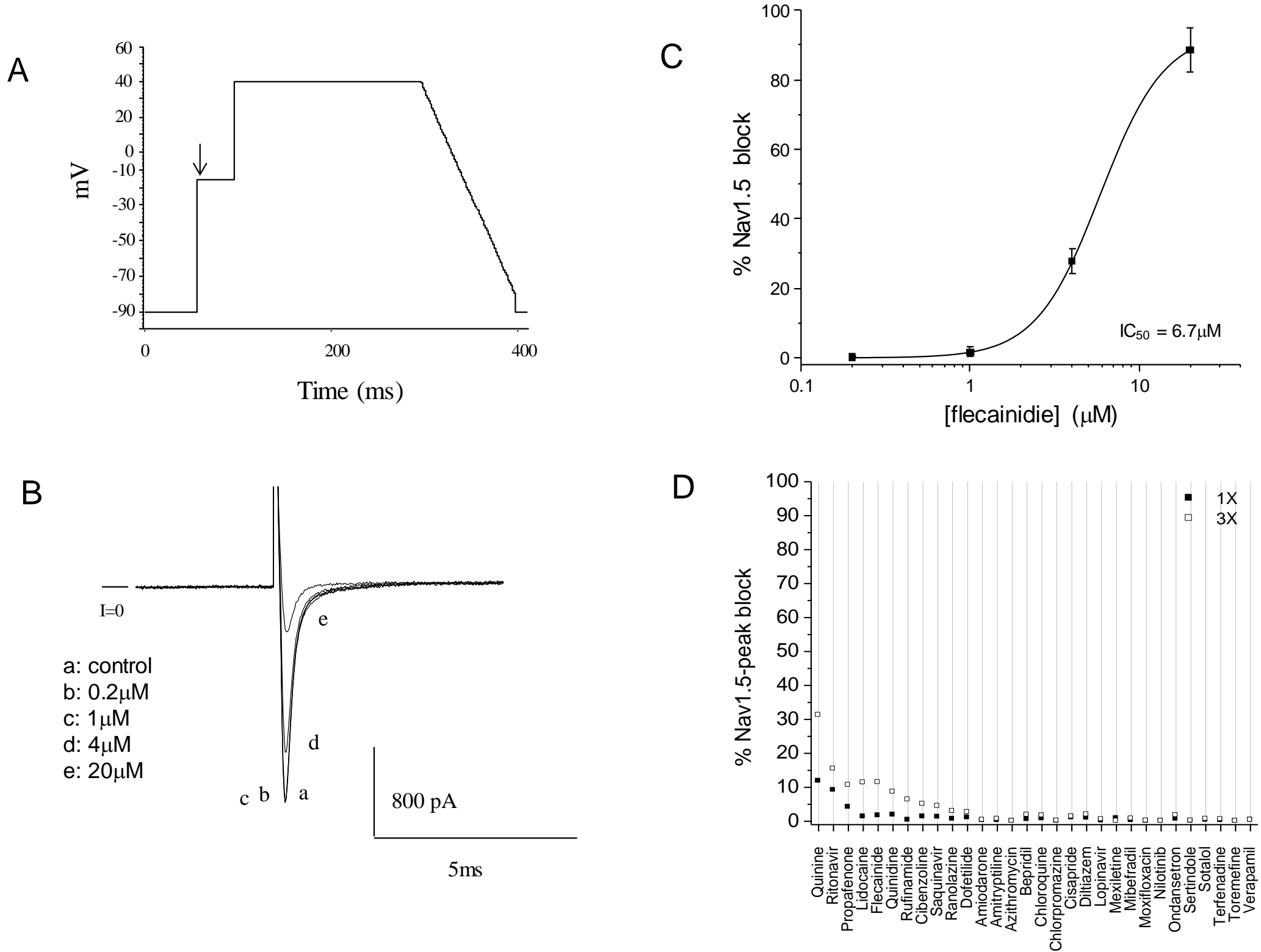
Figure 4: Nav1.5-peak current ( $\mathrm{I}_{\mathrm{N}} \mathrm{a}$-peak) block by the 30 drug panel. A. Voltage protocol used to elicit current at $36 \pm 1^{\circ} \mathrm{C}$. Arrow indicates where current was measured. B. Example of the effects of flecainide on Nav1.5-peak current. Only current during the step to $-15 \mathrm{mV}$ is shown. Peak inward current at the beginning of the step to $-15 \mathrm{mV}$ was measured. C. Concentration-response relationship for flecainide block of Nav1.5-peak. Fit equation is given in the

Methods. D. Amount of Nav1.5-peak current block produced by 1,3X multiples of $\mathrm{C}_{\max }$ free plasma concentrations for each member of the 30 drug panel (data derived from Tables in Supplement). 
A

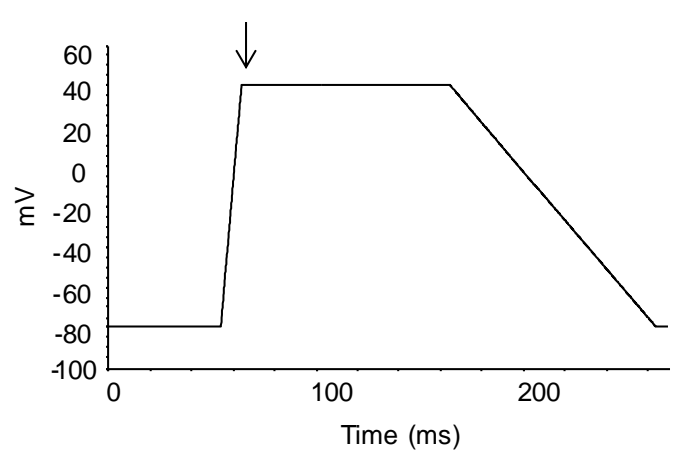

B

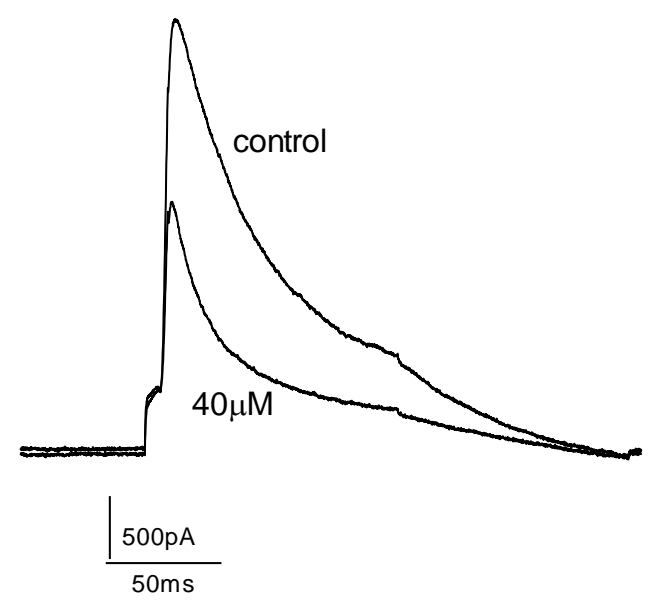

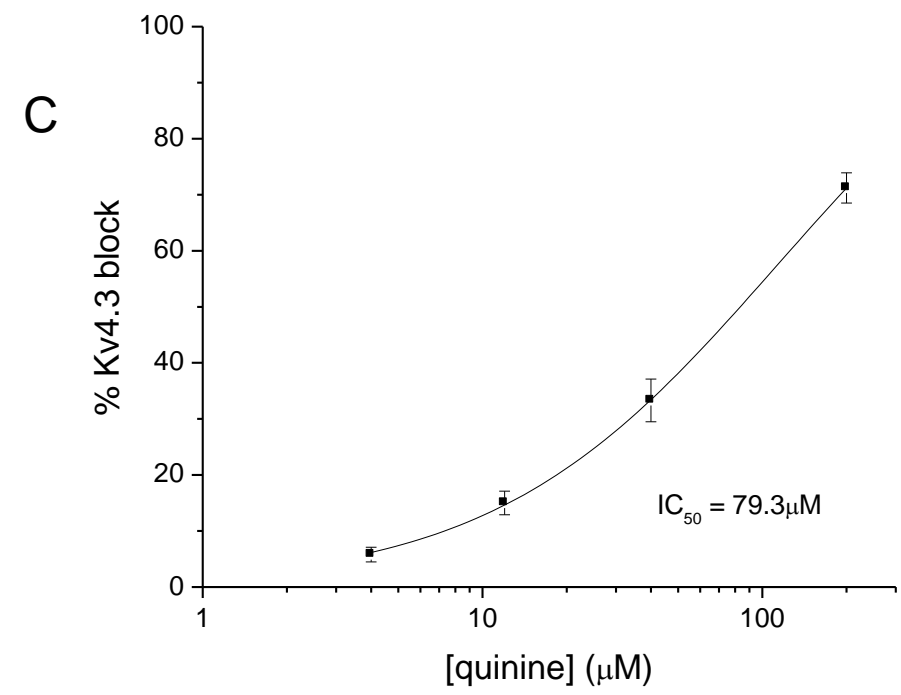

$\mathrm{D}$

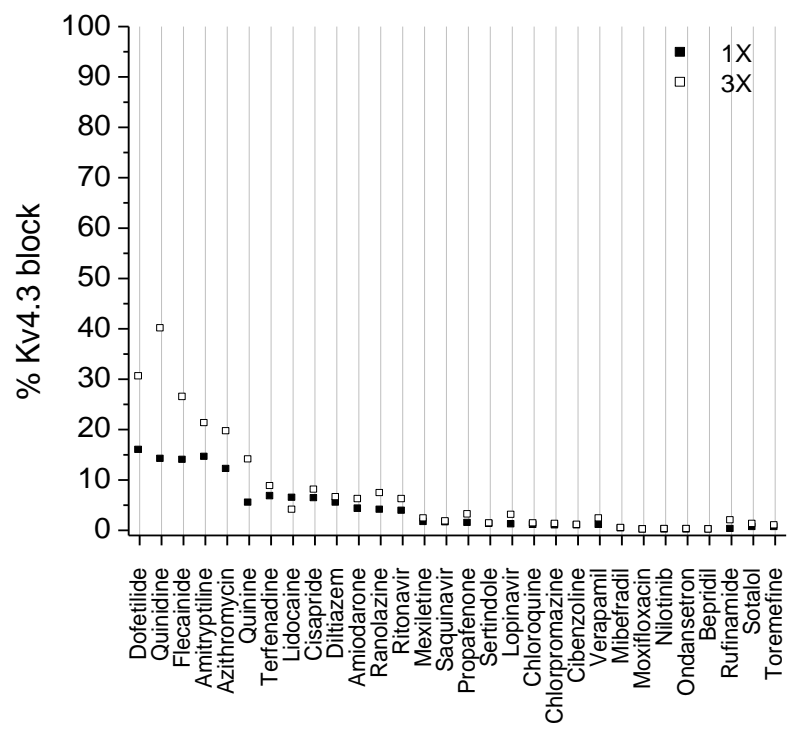

Figure 5: $\quad$ Kv4.3 current $\left(\mathrm{I}_{\mathrm{to}}\right)$ block by the 30 drug panel. A. Voltage protocol used to elicit current at $22 \pm 1{ }^{\circ} \mathrm{C}$. Arrow indicates where current was measured. B. Example of the effects of quinine on Kv4.3-peak current. Peak outward current was measured. C. Concentration-response relationship for quinine block of Kv4.3. Fit equation is given in the Methods. D. Amount of Kv4.3 current block produced by 1, $3 \mathrm{X}$ multiples of $\mathrm{C}_{\max }$ free plasma concentrations for each member of the 30 drug panel (data derived from Tables in Supplement). 
A

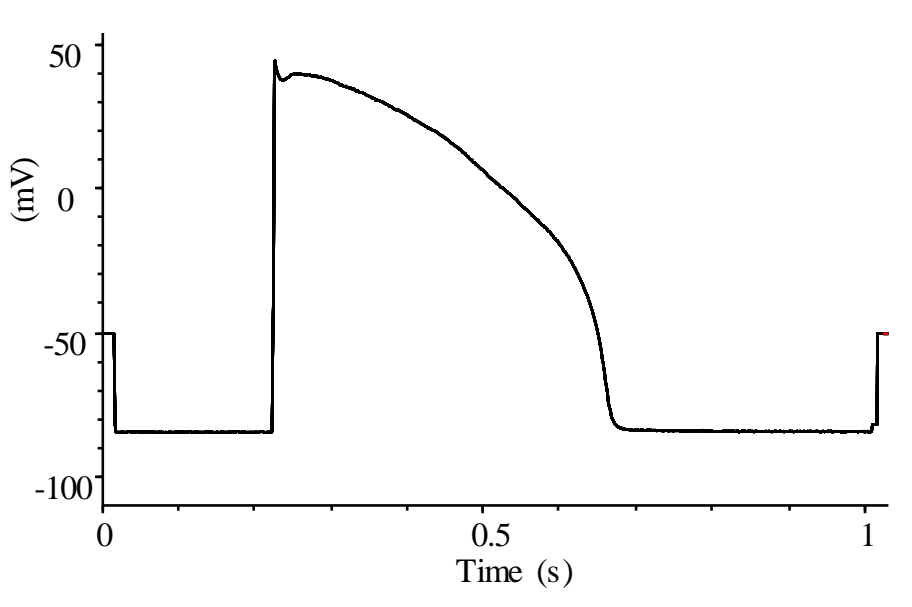

B

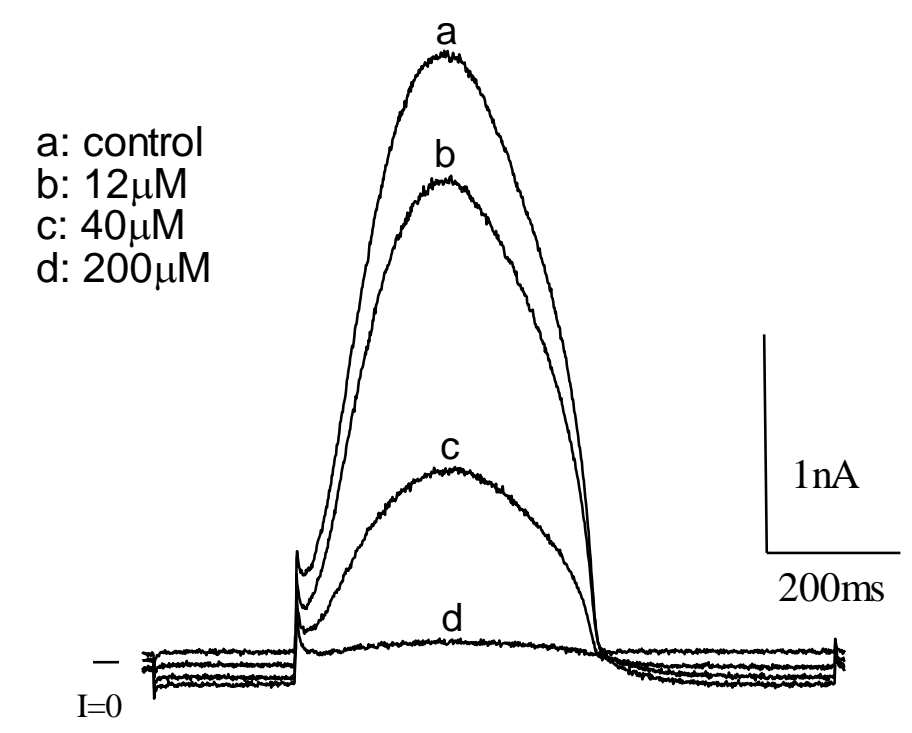

C

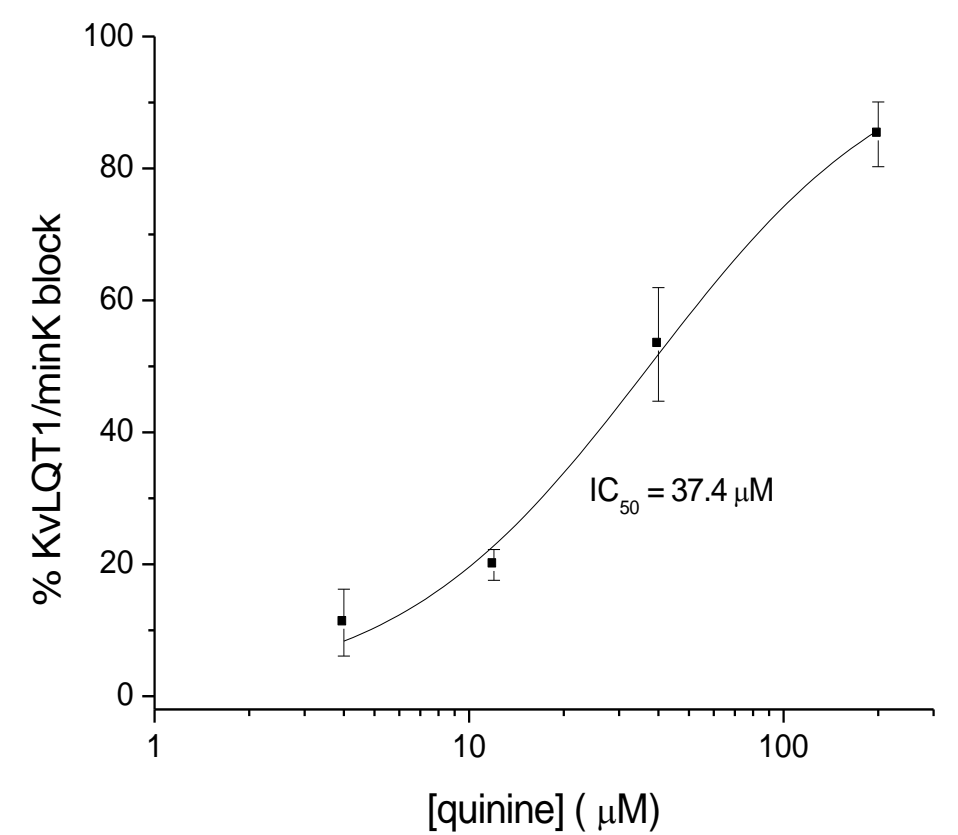

D

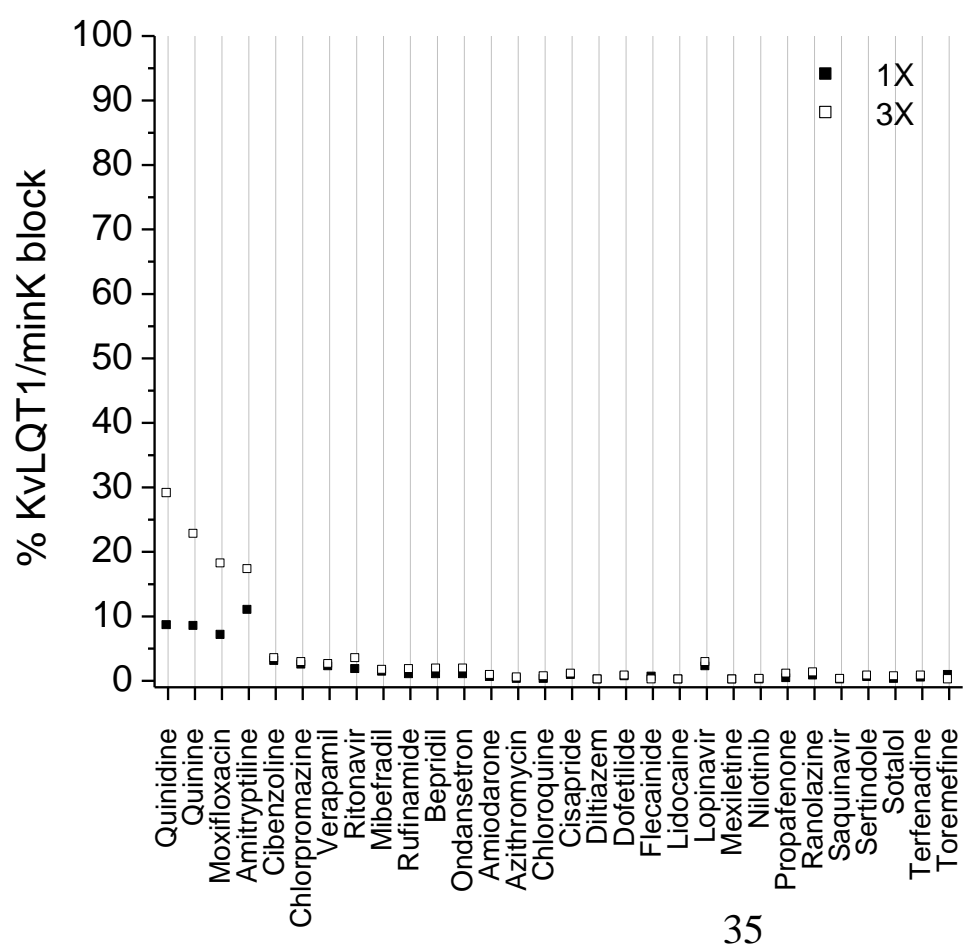


Figure 6: $\quad$ KvLQT1/minK current $\left(\mathrm{I}_{\mathrm{Ks}}\right)$ block by the 30 drug panel. A. Voltage protocol used to elicit current at $36 \pm 1{ }^{\circ} \mathrm{C}$. B. Example of the effects of quinine on

KvLQT1/minK-peak current. Peak outward current was measured. C. Concentration-response relationship for quinine block of KvLQT1/minK. Fit equation is given in the Methods. D. Amount of KvLQT1/minK current block produced by 1, 3X multiples of $\mathrm{C}_{\max }$ free plasma concentrations for each member of the 30 drug panel (data derived from Tables in Supplement). 
A

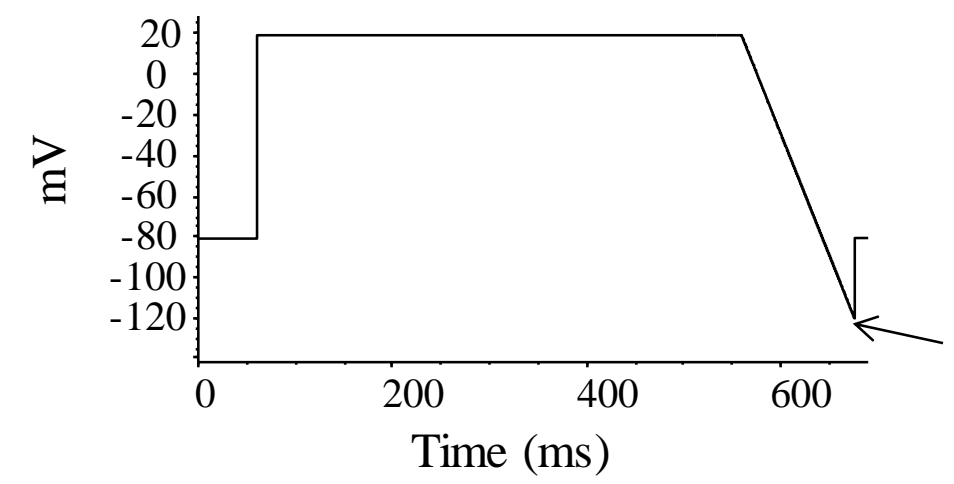

B

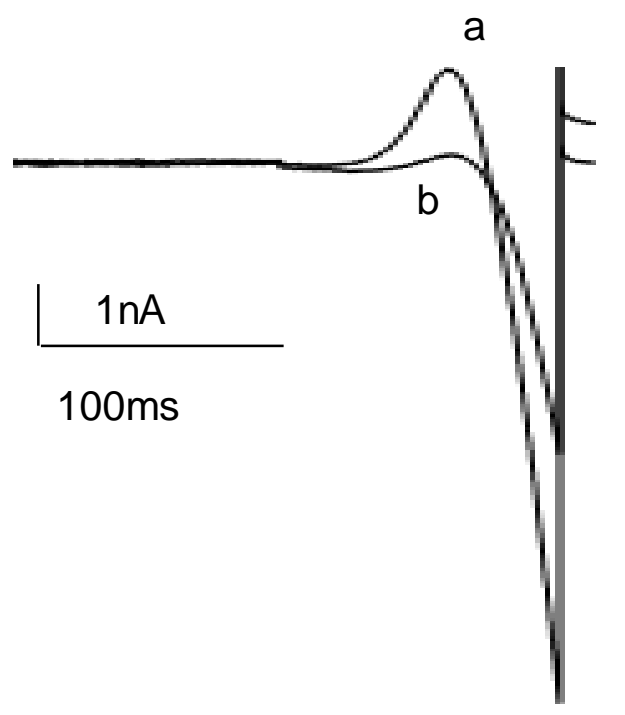

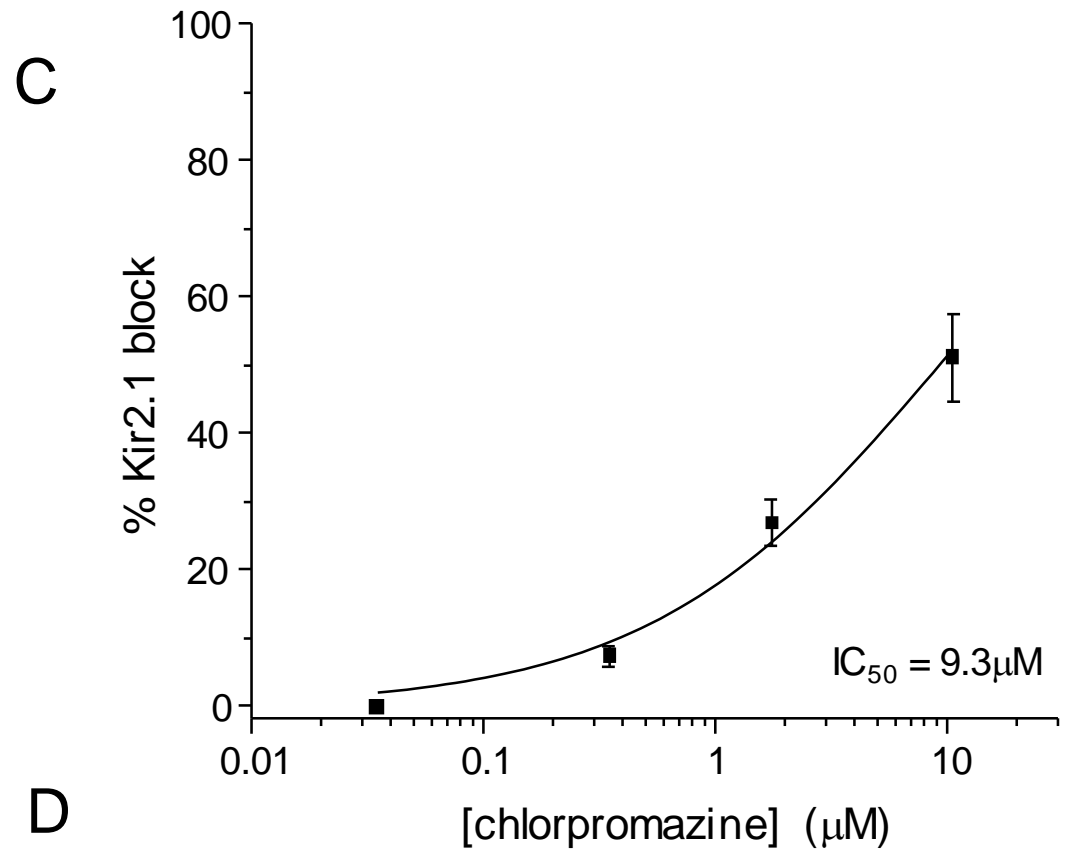

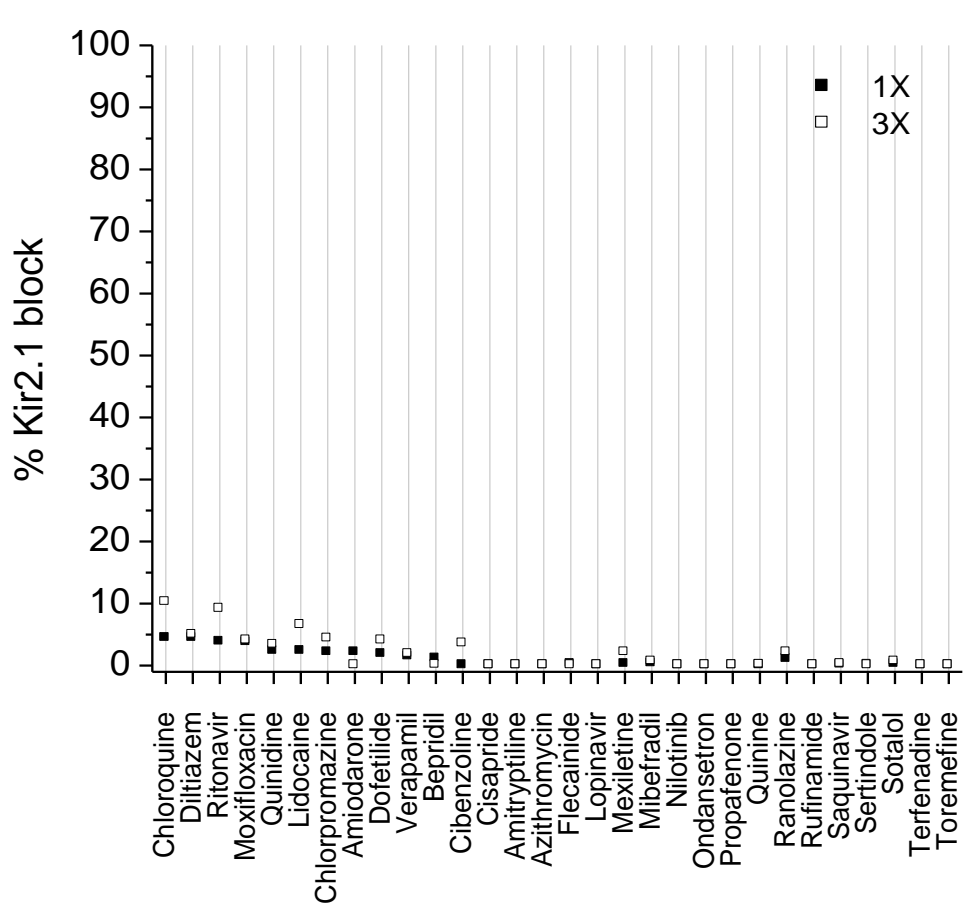


Figure 7: Kir2.1 current $\left(\mathrm{I}_{\mathrm{K} 1}\right)$ block by the 30 drug panel. A. Voltage protocol used to elicit current at $36 \pm 1^{\circ} \mathrm{C}$. Arrow indicates where current was measured. B.

Example of the effects of chlorpromazine on Kir 2.1 current. Trace is truncated to show current during ramp to $-120 \mathrm{mV}$. Peak inward current was measured at $-120 \mathrm{mV}$ at the end of the ramp. C. Concentration-response relationship for chlorpromazine block of Kir2.1. Fit equation is given in the Methods. D. Amount of Kir2.1 current block produced by 1, $3 \mathrm{X}$ multiples of $\mathrm{C}_{\max }$ free plasma concentrations for each member of the 30 drug panel (data derived from Tables in Supplement). 
A

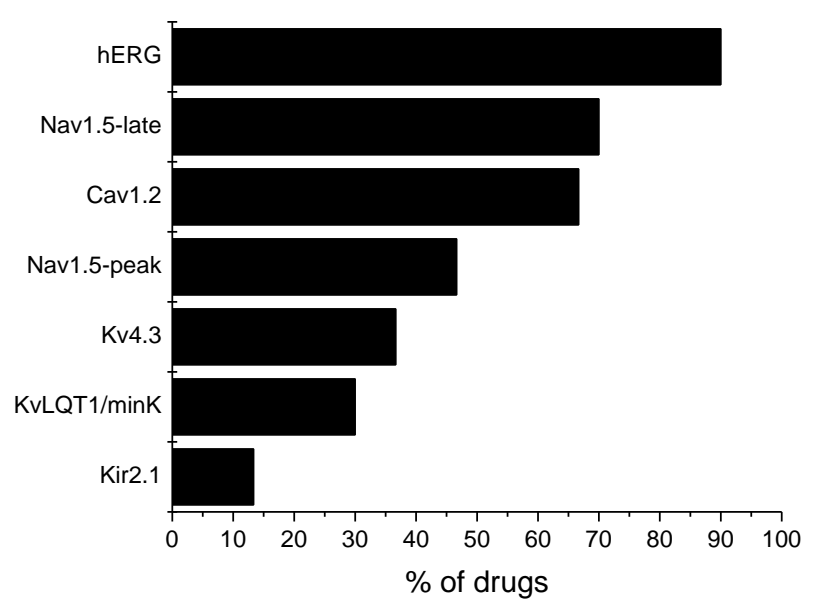

B

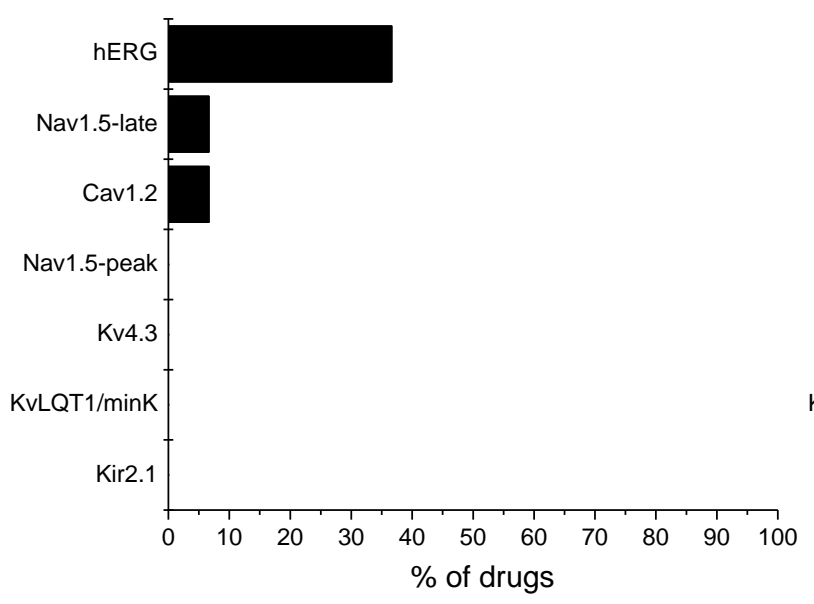

C

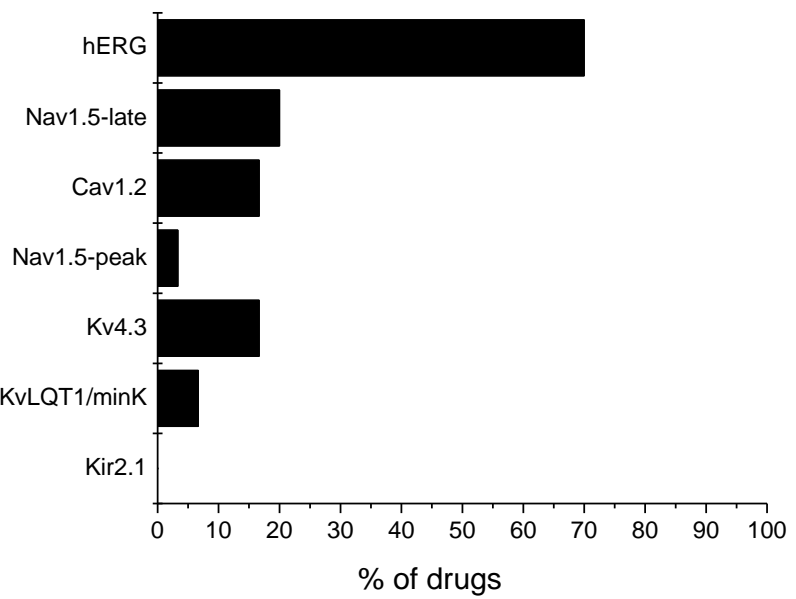

Figure 8: $\quad$ Relative ion current panel activity. Plot of the $\%$ of drugs out of 30 which blocked the indicated ion currents by at least $20 \%$ at any of the concentrations tested (A), at $1 \mathrm{X}$ the free plasma $\mathrm{C}_{\max }(\mathrm{B})$, and at $3 \mathrm{X}$ the free plasma $\mathrm{C}_{\max }(\mathrm{C})$. Reference data was obtained from tables in the Supplement. 

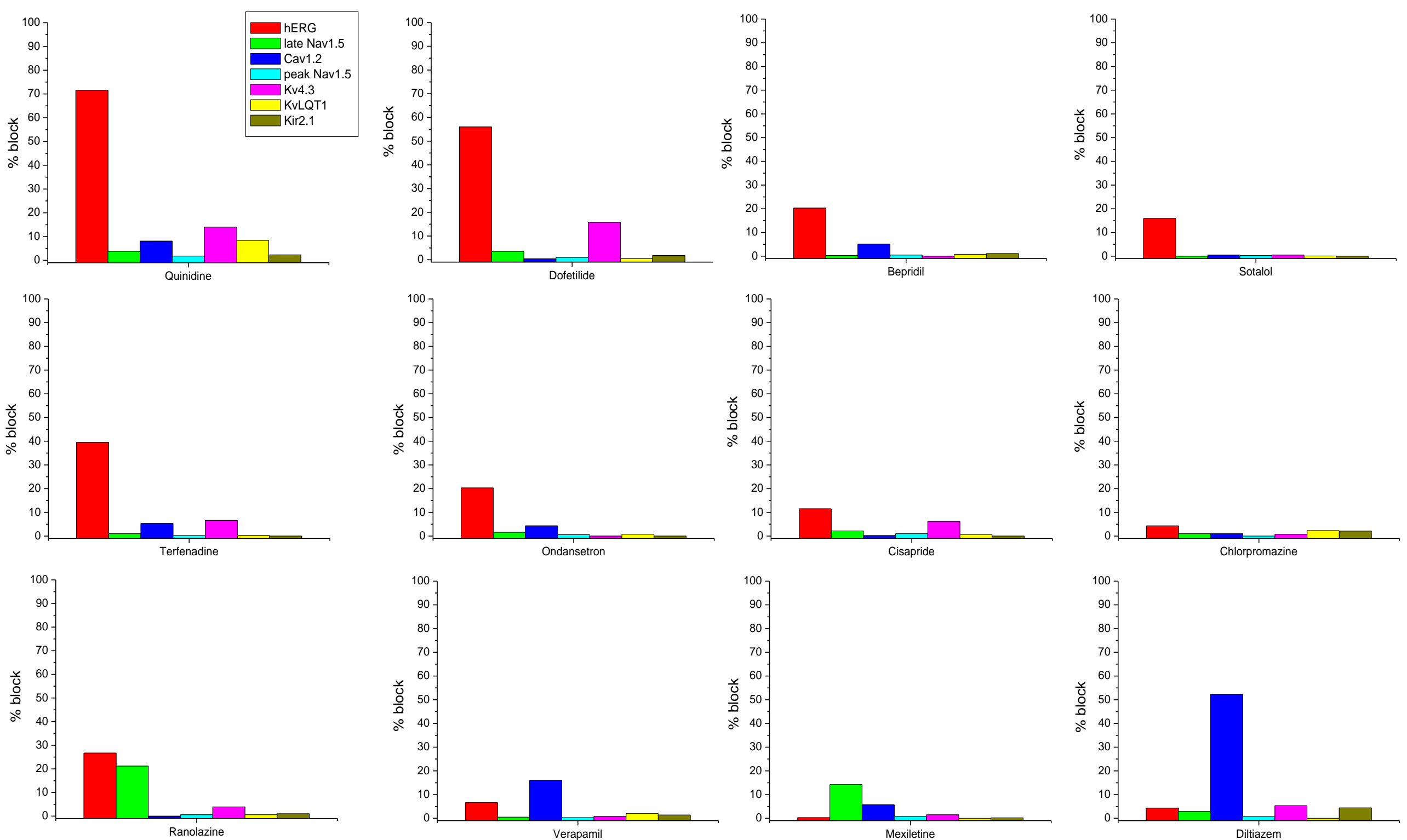

Figure 9. Plot of the ion channel blocking profile of members of the high (top row), intermediate (middle row), and low (bottom row) CiPA proarrhythmic risk categories. $\%$ block represents block at $1 \mathrm{X}$ free plasma $\mathrm{C}_{\max }$. Data was derived from Tables in the Supplement. The $\mathrm{C}_{\max }$ chosen for terfenadine was 9nM, a concentration achieved after metabolic inhibition. A more standard Cmax of $0.3 \mathrm{nM}$ is only associated with $8 \% \mathrm{hERG}$ block. 

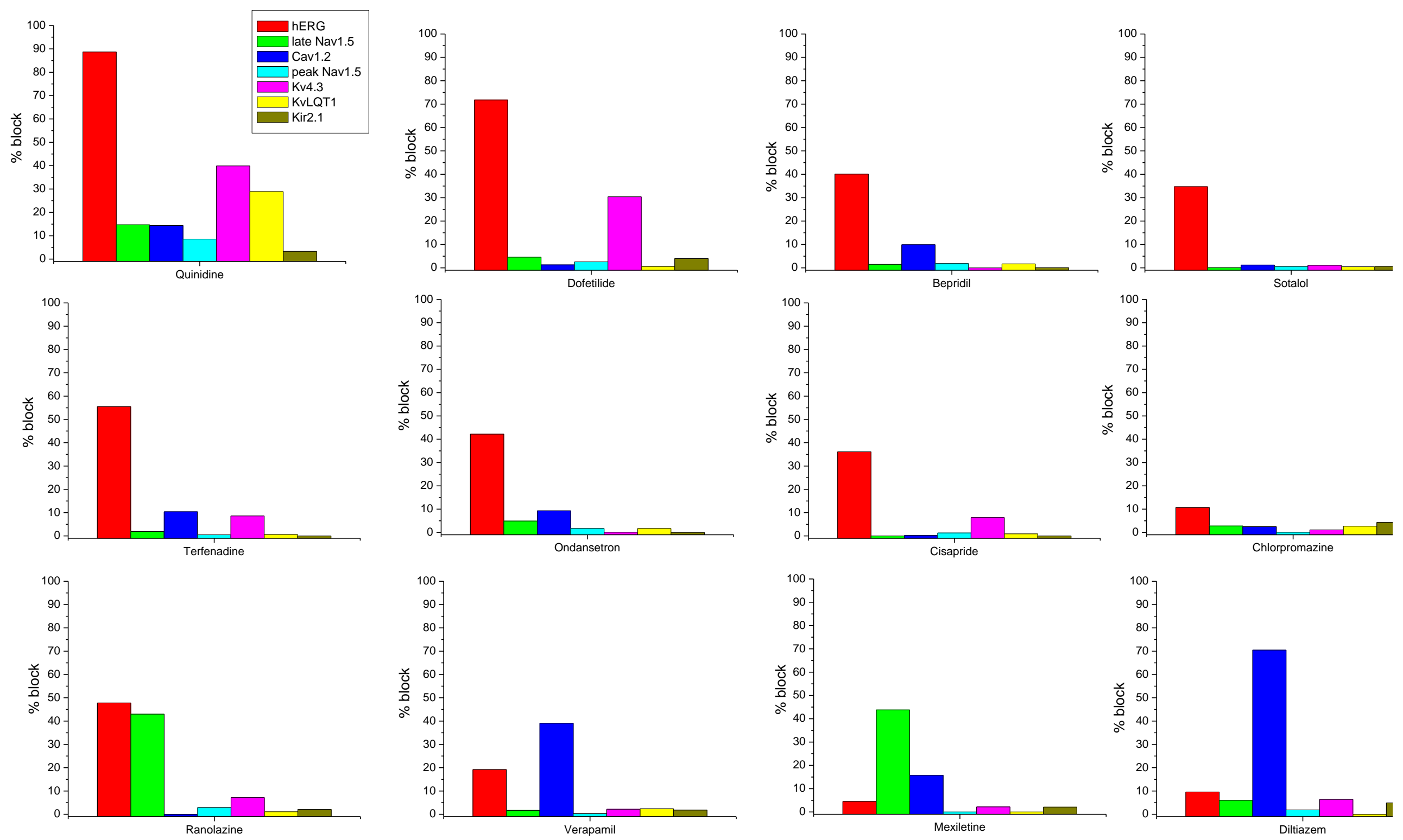

Figure 10. Plot of the ion channel blocking profile of members of the high (top row), intermediate (middle row), and low (bottom row) CiPA proarrhythmic risk categories. $\%$ block represents block at $3 \mathrm{X}$ free plasma $\mathrm{C}_{\max }$. Data was derived from Tables in the Supplement. 